Supporting Information

\title{
Ophthalmic Drops with Nanoparticles Derived from a Natural Product for Treating Age- Related Macular Degeneration
}

\author{
Guang Xin, ${ }^{\dagger}$ Ming Zhang, ${ }^{\ddagger}$ Zhihui Zhong, ${ }^{\dagger}$ Li Tang, $^{\ddagger}$ Yuliang Feng, $^{\ddagger}$ Zeliang Wei, ${ }^{\dagger}$ Shiyi $\mathrm{Li}^{\dagger}{ }^{\dagger}$ \\ Youping Li, ${ }^{\dagger}$ Junhua Zhang, ${ }^{\S}$ Boli Zhang, ${ }^{\S}$ Meng Zhang, " Nelson Rowell, $\perp$ Zhen Chen, ${ }^{\dagger}$ \\ Hai Niu, ${ }^{*}, \Delta$ Kui Yu, ${ }^{*}, \#$ and Wen Huang ${ }^{*},+$
}

'Laboratory of Ethnopharmacology, West China School of Medicine, West China Hospital, Sichuan University, Chengdu, Sichuan 610041, P. R. China

${ }^{\ddagger}$ Department of Ophthalmology, West China School of Medicine, West China Hospital, Sichuan University, Chengdu, Sichuan 610041, P. R. China

$\S$ Tianjin University of Traditional Chinese Medicine, Tianjin, 300193, P. R. China

"Institute of Atomic and Molecular Physics,

Sichuan University, Chengdu, Sichuan 610065, P. R. China

${ }^{\perp}$ Metrology Research Centre, National Research Council Canada, Ottawa, Ontario K1A 0R6, Canada

${ }^{\Delta}$ College of Mathematics, Sichuan University, Chengdu, Sichuan 610065, P. R. China

\#Engineering Research Center in Biomaterials, Sichuan University, Chengdu, Sichuan 610065, P. R. China

Correspondence and requests for materials should be addressed to Hai Niu (E-mail: niuhai@scu.edu.cn), Kui Yu (E-mail: kuiyu@scu.edu.cn), and Wen Huang (First corresponding author; E-mail: huangwen@scu.edu.cn) 
Table of Contents

Experimental Methods

Synthesis of Boc-6-aminohexanoic acid $\quad S-3$

Synthesis of Boc-6-aminohexanoic acid-Diosgenin $\quad$ S-3

Synthesis and Characterization of ACD $\quad S-3$

Experimental Animals $\quad S-4$

Rhesus Monkey Model of Laser-induced AMD $\quad$ S-4

Physicochemical Characterization of the Materials $\quad S-5$

In Vitro ACD Release $\quad$ S-6

Eye Tissue Distribution and Pharmacokinetic Studies $\quad$ S-6

Cell Culture $\quad S-7$

Tubular Formation Assay $\quad$ S-7

Migration Assay $\quad$ S-7

Western Blot Analysis $\quad$ S-7

Cell Morphological Analysis $\quad \mathrm{S}-8$

GFP-LC3 Transfection $\quad$ S-8

siRNA Transfection $\quad S-8$

Statistical Analysis $\quad$ S-8

Figure S1 Comparison of the anti-choroidal neovascularization activity (CNV) S-9

Table S1 Estimation of the eye injury for the two groups (shown in Figure 1) S-10

Figure S2-1 Preparation and characterization of eye drops $\quad$ S-11

Figure S2-2 Size measurements of ACD nanoparticles up to 21 days $\quad$ S-12

Figure S2-3 Self-assembly of five Dio derivatives explored $\quad$ S-13

Figure S2-4 Exploration of 12 solvents for the ACD self-assembly in water $\quad$ S-14

Figure S2-5 Examination of $\beta$-cyclodextrin amounts for the ACD self-assembly $\quad$ S-15

Figure S3 Comparison of the release of ACD shown in Figure $3 \quad$ S-16

Figure S4 Pharmacokinetic studies of ACD in rats' plasma $\quad$ S-17

Table S2 Summary of pharmacokinetic data for plasma ACD in rats S-18

Figure S5-1 Optical microscope images for Figure 5a $\quad$ S-19

Figure S5-2 In vivo toxicity study $\quad$ S-20

Figure S5-3 Effect of EDTA on the in vitro anti-angiogenic activity of samples S-21

Figure S6-1 Quantitative analysis of LC3II/LC3I for Figure 6a Western blots S-22

Figure S6-2 RPE cell explored for 1,25D3-MARRS and autophagy $\quad$ S-23

Figure S6-3 Evaluation of the advantages of eye drops $\quad$ S-24

Figure S7 Quantitative analysis for Figures 7b and 7c $\quad$ S-25

Note Design and preparation of ACD eye drops $\quad$ S-26

$\begin{array}{lr}\text { REFERENCES } & \text { S-27 }\end{array}$ 


\section{Experimental Methods}

Synthesis of Boc-6-aminohexanoic acid. Boc-6-aminohexanoic acid (Figure S2-4a Step 1) was synthesized following a procedure reported. ${ }^{1}$ 6-aminohexanoic acid (1.31 g) and (Boc) ${ }_{2} \mathrm{O}(2.18$ g) were added in a mixture of acetone and water $(\mathrm{v}: \mathrm{v}, 1: 1,400 \mathrm{~mL})$ in the presence of $\mathrm{Et}_{3} \mathrm{~N}(2.8$ $\mathrm{mL}$ ). The mixture was reacted for $5 \mathrm{~h}$ at $37^{\circ} \mathrm{C}$. Then, acetone was removed with the rotary evaporator, and the water residue was acidified with dilute $\mathrm{HCl}$ to $\mathrm{pH} 4-5$. The combined organic phase was separated and washed with brine, and dried over anhydrous $\mathrm{Na}_{2} \mathrm{SO}_{4}$. Finally, the organic phase was concentrated in vacuo to obtain Boc-6-aminohexanoic acid ( $2.58 \mathrm{~g}$, the yield is $98 \%)$ as white solid under $4{ }^{\circ} \mathrm{C}$.

Synthesis of Boc-6-aminohexanoic acid-Diosgenin. Diosgenin (Dio, 0.83 g), Boc-6aminohexanoic acid (0.60 g), p-toluenesulfonic acid ( $\mathrm{TsOH}, 0.07 \mathrm{~g})$ and 4dimethylaminopyridine (DMAP, $0.05 \mathrm{~g}$ ) were mixed in anhydrous $\mathrm{CH}_{2} \mathrm{Cl}_{2}(20 \mathrm{~mL})$, in which a solution of $\mathrm{N}, \mathrm{N}^{\prime}$-dicyclohexylcarbodiimide (DCC, $0.62 \mathrm{~g}$ ) in anhydrous $\mathrm{CH}_{2} \mathrm{Cl}_{2}(6 \mathrm{~mL})$ was added dropwise under $\mathrm{N}_{2}$ atmosphere at $37{ }^{\circ} \mathrm{C}$. Then, the mixture was stirred for $9 \mathrm{~h}$ at the same temperature (Figure S2-1a Step 2). The resulting mixture was filtered, and the filtrate was washed with the saturated $\mathrm{NaHCO}_{3}$ solution, followed by filtration and concentration. The residue was purified by a silica gel column chromatography (petroleum ether : EtOAc $=15: 1$ ) to obtain Boc-6-aminohexanoic acid-Diosgenin (1.18 g, the yield is $94 \%$ ) as a white powder., ${ }^{1,2}$

Synthesis and Characterization of ACD. In a solution of Boc-6-aminohexanoic acid-Diosgenin (1.00 g) in $\mathrm{CH}_{2} \mathrm{Cl}_{2}(20 \mathrm{~mL})$, trifluoroacetic acid $\left(\mathrm{CF}_{3} \mathrm{COOH}, 1.2 \mathrm{~mL}\right)$ was added, and the mixture was stirred at $37^{\circ} \mathrm{C}$ for $6 \mathrm{~h}$ (Figure S2-1a Step 3). The resulting mixture was neutralized by adding triethylamine $\left(\mathrm{Et}_{3} \mathrm{~N}, 2 \mathrm{~mL}\right)$ at $0{ }^{\circ} \mathrm{C}$. The organic layer was washed with the brine, and was dried over anhydrous $\mathrm{Na}_{2} \mathrm{SO}_{4}$. The reaction mixture was purified by flash chromatography using EtOAc and hexane to obtain ACD $\left(0.74 \mathrm{~g}\right.$, the yield is $88 \%, \mathrm{H}_{2} \mathrm{~N}-\left(\mathrm{CH}_{2}\right) \mathrm{n}-\mathrm{COO}$-Dio with $\left.\mathrm{n}=5\right)$ as a light yellow solid. By an aside, Compounds $1-4$, with respective $n=1,3,7$, and 11 , were also synthesized via a similar approach.

The purity of ACD was determined by high-performance liquid chromatography (HPLC, Shimadzu Japan), and which was above $98 \% .{ }^{1} \mathrm{R}_{\mathrm{f}}=0.46\left(\mathrm{CH}_{2} \mathrm{Cl}_{2}: \mathrm{CH}_{3} \mathrm{OH}=5: 1\right) ;{ }^{1} \mathrm{H} \mathrm{NMR}(400$ $\left.\left.\mathrm{MHz}_{\mathrm{CDCl}}\right)\right) 5.56(\mathrm{~s}, 1 \mathrm{H}), 5.37(\mathrm{~d}, \mathrm{~J}=3.5 \mathrm{~Hz}, 1 \mathrm{H}), 4.65-4.49(\mathrm{~m}, 1 \mathrm{H}), 4.41(\mathrm{dd}, \mathrm{J}=14.8,7.3 \mathrm{~Hz}$, 
1H), 3.55 (q, J = 7.2 Hz, 2H), $3.51-3.43(\mathrm{~m}, 1 \mathrm{H}), 3.37$ (t, J=10.9 Hz,1H), $3.07-2.89(\mathrm{~m}, 2 \mathrm{H})$, $2.29(\mathrm{t}, \mathrm{J}=7.8 \mathrm{~Hz}, 4 \mathrm{H}), 2.07-1.93(\mathrm{~m}, 2 \mathrm{H}), 1.02(\mathrm{~d}, \mathrm{~J}=9.4 \mathrm{~Hz}, 3 \mathrm{H}), 0.97(\mathrm{~d}, \mathrm{~J}=6.7 \mathrm{~Hz}, 3 \mathrm{H}), 0.79$ (s, 6H); ${ }^{13} \mathrm{C}$ NMR $\left(100 \mathrm{MHz}, \mathrm{CDCl}_{3}\right) \delta \mathrm{s} 7172.94,139.71,122.31,109.25,80.78,73.79,66.81$, 62.07, 56.42, 52.95, 49.92, 41.59,40.24, 39.71, 39.68, 38.08, 36.94, 36.71, 34.32, 32.03, 31.83, $31.38,30.27$, 28.79,27.74, 27.19, 26.08, 24.37, 20.80, 19.34, 17.13, 16.28, 14.52, 8.18; HR$\mathrm{MS}(\mathrm{m} / \mathrm{z})$ Calcd for $\mathrm{C}_{33} \mathrm{H}_{53} \mathrm{NO}_{4}: 528.4053[\mathrm{M}+\mathrm{H}]^{+}$, found: $528.4072[\mathrm{M}+\mathrm{H}]^{+}$.

${ }^{1} \mathrm{H}$ NMR and ${ }^{13} \mathrm{C}$ NMR spectra were recorded on Varian UNITY INOVA or Bruker AV II spectrometer at $400 \mathrm{MHz}$ using tetramethyl silane as an internal standard. The chemical shifts $(\delta)$ were reported in ppm and coupling constants $(J)$ in $\mathrm{Hz}$. High resolution mass spectra (HRMS) were obtained with ESI-Q-TOF-MS (Bruker, Germany).

Experimental Animals. All animal experiments were performed in accordance with the guidelines for the care and use of laboratory animals. All protocols were approved by the 'Institutional Animal Care and Use Committee of Sichuan University' and the approval number for the animal experiments is 2014008B. Wistar rats (male, $200 \pm 20 \mathrm{~g}$ ), New Zealand white rabbits (male, 2.5 - $3.0 \mathrm{~kg}$ ), and Macaca rhesus monkeys (male, 5 - 6 years of age, 5 - $7 \mathrm{~kg}$ ) were obtained by 'Experimental Animal Research Center, Sichuan University'. The animals had free access to standard laboratory chow and water at $22 \pm 2{ }^{\circ} \mathrm{C}$ with a $12 \mathrm{~h} \mathrm{light/dark}$ cycle. All surgeries were performed under anesthesia, and all efforts were made to minimize suffering and the number of animals used. ${ }^{3}$

Rhesus Monkey Model of Laser-induced AMD. Laser-induced choroidal neovascularization (CNV) rhesus monkey model was performed as previous reported with some modifications..$^{4-7}$ In brief, baseline fundus photography and mydriasis were performed for ocular health screening. Rhesus monkeys (male, 5 - 6 years of age, 5 - $7 \mathrm{~kg}$ ) were anaesthetized with pentobarbitone (25 $\mathrm{mg} / \mathrm{kg}$ ). Topical ocular anesthesia was performed with proparacaine $(1 \mathrm{mg} / \mathrm{mL})$, pupil dilation was dilated by tropicamide $(5 \mathrm{mg} / \mathrm{mL})$, and eyes moist was kept using carboxymethylcellulose sodium (10 mg/mL). Under anesthesia, eight laser spots were applied around the perivascular region by a laser photocoagulation system (Vissulus 532s; Carl Zeiss). The laser parameters were as follows: wavelength of $532 \mathrm{~nm}$, the spot size of $50 \mathrm{~mm}$, pulse duration of $0.05 \mathrm{~s}$, and laser power of $0.5 \mathrm{~W}$. 
Under anesthesia, fluorescein fundus angiography (FFA) was applied by sodium fluorescein solution $(10 \%, 0.05 \mathrm{~mL} / \mathrm{kg})$ via the vein of the lower limbs. A series of photographs were taken by a fundus camera (FF450 plus IRu Retina Camera, Carl Zeiss) to evaluate fluorescein leakage associated with CNV lesions at 3-5 minutes after injection fluorescein solution. The CNV area around each laser injury was measured by the ImageJ software. The 3 areas obtained in each eye were averaged to give a single experimental value. Under sedation, optical coherence tomography (OCT) scan was applied by Stratus OCT model 3000 (Carl Zeiss Medited Inc). It was established that the eye reaches the maximum damage range at 14 days post laser photocoagulation. ${ }^{8}$ The macular thickness was measured by the fast-macular thickness mapping protocol of Stratus OCT (Carl Zeiss Meditec). A topographical map of the macula was generated with the Stratus OCT software. The map is composed of 9 sectorial thickness measurements in 3 concentric circles with diameters of 1,3 , and $6 \mathrm{~mm}$. It is important to note that the central $1 \mathrm{~mm}$ circular region represents the foveal area. ${ }^{9}$

The twice a daily treatment was carried out up to 28 days, with $50 \mu \mathrm{L}$ of saline (control), ACD solution ( $1 \mathrm{mg} / \mathrm{mL}$ ), ACD nanoparticles ( $1 \mathrm{mg} / \mathrm{mL}$, based on the amount of ACD), and the eye drops ( $1 \mathrm{mg} / \mathrm{mL}$, based on the amount of ACD). Respectively, three (six eyes), one (two eyes), one (two eyes), and 4 (eight eyes) animals were used from 14 to $42 \mathrm{~d}$ after the laser injury. After 14, 28, 35, 42 days of the laser photocoagulation, FFA and OCT images were collected to evaluate CNV. CNV was rated on the scale of I to IV, where I = nohyper fluorescence, II = hyper fluorescence without leakage, III = hyper fluorescence early or mid-transit with late leakage, and IV = hyper fluorescence early or mid-transit with late leakage extending beyond the borders of the treated area. At $42 \mathrm{~d}$ after laser injury, immunohistochemical analysis for choroidal blood vessels was performed as previously described (for only the saline and eye drop treatment (Figure S1-1)). ${ }^{7}$ The ocular posterior pole was dissected, and the section that contained lesions of interest was prepared for hematoxylin and eosin (H\&E) staining. Then Biotinylated lectin (Vector Laboratories, Biotinylated Lycopersicon Esculentum Lectin) was used to label blood vessels.

Physicochemical Characterization of the Materials. The morphology of the nanoparticles and eye drops was evaluated by transmission electron microscope (TEM) (Cypher VRS, Oxford 
Instruments), scanning electron microscope (SEM) (JSM-7500F, JEOL, Ltd.) at 200 kV. Fourier transform infrared (FTIR) spectroscopy (Nicolet 6700, Thermo Fisher Scientific), X-ray diffraction (XRD) ( DX-1000, Dandong Fangyuan Instrument Co., Ltd.), and thermogravimetric analysis (TGA) (STA 449 F3 Jupiters, NETZSCH) were performed. ${ }^{10}$ Nano-Particle Size Analyzer (LB-550, Horiba Ltd) was used to study the particle size and distribution of ACD nanoparticles (1 mg/mL).

In Vitro ACD Release. In vitro release of ACD molecules from the free solution, nanoparticles or eye drops was evaluated by a dynamic dialysis method. ${ }^{11}$ An aliquot $(1 \mathrm{~mL})$ of the ACD free solution $(1 \mathrm{mg} / \mathrm{mL})$, nanoparticles solution $(1 \mathrm{mg} / \mathrm{mL})$ and eye drops $(1 \mathrm{mg} / \mathrm{mL}$, based on the amount of ACD) was placed in the mini dialysis kits ( $2 \mathrm{~mL}$, MWCO 8kDa cut-off, GE Health, USA) and floated in $100 \mathrm{~mL} \mathrm{pH}=7.4$ phosphate buffer saline (PBS) or $\mathrm{pH}=5.2$ buffer (PBS solution containing $0.1 \mathrm{wt} \%$ Tween 80 ) medium. Then, the samples were maintained at $37^{\circ} \mathrm{C}$ with a paddle revolution speed of $100 \mathrm{rpm} / \mathrm{min}$ in G24 Environmental incubator shaker (New Brunswick Scientific Co. Inc.). At intervals, $100 \mu \mathrm{L}$ fresh release medium was added to the bulk solution after $100 \mu \mathrm{L}$ of release sample was withdrawn. The concentration of ACD from the released sample was analyzed by UHPLC-MS/MS (Acquity UPLC system coupled to a Xevo TQ-S mass spectrometer, Waters). The data of in vivo release profiles was normalized.

Eye Tissue Distribution and Pharmacokinetic Studies. ACD eye drops were administrated into eyes of New Zealand White rabbits (male, 2.5 - 3.0 kg) at a single dose of ACD eye drops (1 $\mathrm{mg} / \mathrm{mL}, 50 \mu \mathrm{L} /$ eye). Then rabbits were anesthetized and sacrificed at indicated time after drug administration. Eyes were enucleated, and vitreous body, retina and choroid tissues were carefully separated. For choroid and retina samples, they were weighed, homogenized in acetonitrile. The concentrations of ACD in the fundus were monitored by UHPLC-MS/MS system (Acquity UPLC system coupled to a Xevo TQ-S mass spectrometer, Waters).

Wistar rats (male, 200-220 g) were anesthetized with pentobarbital sodium $(50 \mathrm{mg} / \mathrm{kg}$ ) via intraperitoneal administration. The right jugular vein was catheterized with polyethylene tubing for blood sampling. After $24 \mathrm{~h}$ of surgery, ACD eye drops were administered intravenously ( 2 $\mathrm{mg} / \mathrm{kg}$ ) or intraperitoneally $(20 \mathrm{mg} / \mathrm{kg}$ ) at a single dose, respectively. Blood samples (300 $\mu \mathrm{L})$ were collected in heparin-rinsed eppendorf vials from the jugular vein at indicated time. The concentrations of plasma ACD were monitored by UHPLC-MS/MS system (Acquity UPLC system 
coupled to a Xevo TQ-S mass spectrometer, Waters). Serum pharmacokinetic analysis of concentration-time data were calculated using Winnonlin Phoenix software (Pharsight) with two-compartment and non-compartment models for intravenous and intraperitoneal administration group, respectively. ${ }^{12}$

Cell Culture. Primary human umbilical vein endothelial cells (HUVECs) were kindly gifted by Laboratory of Transplantation Immunity, Sichuan University. HUVEC cells were maintained in complete EGM-2 medium supplemented with $2 \%$ FBS and EGM-2 Single Quots kit (Lonza). ${ }^{13}$ In the experiments, cells were starved for $6-18 \mathrm{~h}$ in serum-free medium before treated with indicated concentrations of the eye drops. PBS was used as vehicle control. Unless otherwise noted, VEGF-induced (incubated) HUVECs mean that cells were preincubated with exogenous $20 \mathrm{ng} / \mathrm{mL}$ recombinant human VEGF 165 (Pepro Tech. Inc.) in the study. ${ }^{14,15}$

Tubular Formation Assay. 48-well plates were coated with $150 \mu \mathrm{L}$ Matrigel basement membrane matrix (BD Biosciences) and cultivate at $37^{\circ} \mathrm{C}$ for $30 \mathrm{~min}$. After polymerization of the gels, HUVEC cells in serum-free medium with VEGF $(20 \mathrm{ng} / \mathrm{mL})$ were seeded onto the Matrigel and incubated with $A C D$ eye drops $(0.00,1.25,2.50,5.00 \mu \mathrm{M})$ for $24 \mathrm{~h}$. Representative photographs were taken by Axio Observer. D1 inverted microscope (Carl Zeiss) and the length of the tubes in three random microscopic fields was measured by Image-Pro Plus 7.0 software. The tube formation percentage was expressed using control cells at $100 \%$ percentage. ${ }^{16}$

Migration Assay. When HUVECs (or transfected with siControl and siMARRS) were grown into full confluence in complete EGM-2 medium in 24-well plates, a scratch wound was made by using a sterile $200 \mu \mathrm{L}$ pipette tip and washed three times with PBS. Serum-free EGM-2 medium supplemented with VEGF ( $20 \mathrm{ng} / \mathrm{mL}$ ) was added, followed by treatment of ACD eye drops $(0.00,1.25,2.50,5.00 \mu \mathrm{M})$ for $24 \mathrm{~h}$. Images were taken by fluorescence microscope (Olympus IX71). Images of the scratches were acquired after the treatment, and further analyzed using an Axio Observer.D1 inverted microscope (Carl Zeiss). ${ }^{17}$

Western Blot Analysis. For HUVEC cells (or human retinal pigment epithelial cells), they were serum-starved overnight and then incubated with the mixtures of eye drops (5 $\mu \mathrm{M})$ and VEGF $(20 \mathrm{ng} / \mathrm{mL}$ ) for $0,12,18$ and $24 \mathrm{~h}$. Cell lysates were subjected to SDS-PAGE on $10-15 \%$ gels followed by transfer to PVDF membrane. The membranes were incubated with the antibodies 
against 1,25D $\mathrm{D}_{3}$-MARRS/ERp57 (Abcam) and LC3 II/I (Cell Signaling Technology). GAPDH (Santa Cruz Biotechnology) was used as whole-cell extract loading control. The proteins were visualized with enhanced chemiluminescence detection (Amersham Biosciences). ${ }^{18}$

Cell Morphological Analysis. HUVECs were treated with VEGF (20 ng/mL) and PBS (control) or the eye drops (5 $\mu \mathrm{M})$ in complete medium. After $24 \mathrm{~h}$, cells were fixed in glutaraldehyde, osmicated with osmium tetroxide, dehydrated by graded ethanol, embedded in Epon-Araldite resin. Ultrathin sections of samples were cut, double stained and analyzed by H-600IV transmission electron microscope (HITACHI). ${ }^{19,20}$

GFP-LC3 Transfection. Cells were transfected with pEGFP-LC3 plasmid, a gift from State Key Laboratory of Biotherapy, Sichuan University, using Lipofectamine 2000 reagent (Invitrogen, California, United States). After transfection for $48 \mathrm{~h}$, cells were inoculated on the coverslips and treated with the mixtures of VEGF $(20 \mathrm{ng} / \mathrm{mL})$ and PBS or eye drops $(5 \mu \mathrm{M})$ for $24 \mathrm{~h}$. Subsequently, cells were stained with Hoechst 33342 (Invitrogen, California, United States). Then images were taken using a confocal laser scanning microscope (Nikon Eclipse Ti). The average number of GFP-LC3 punctate dots per cell was calculated in at least 50 cells. ${ }^{20}$

siRNA Transfection. siRNA for $1,25 D_{3}$-MARRS (siMARRS, Invitrogen, California, United States) and control siRNA (siControl, without targeting siRNA) were transfected into HUVEC cells using DharmaFECT transfection reagent (Dharmacon, Colorado, United States). ${ }^{21}$ After $48 \mathrm{~h}$ of siRNA transfection, cells lysates were analyzed by $1,25 D_{3}$-MARRS/ERp57 antibody (Abcam, Cambridge, United Kingdom) to confirm the knockdown of $1,25 D_{3}$-MARRS.

Statistical Analysis. Statistical analysis was performed with unpaired two-tailed t-test using Graphpad Prism 5 (Graphpad Software) when two individual experimental groups were analyzed. For multiple comparisons, one way ANOVA with Dunnett's multiple comparison test, Bonferroni's post hoc multiple comparison tests and two-way repeated measures ANOVA were used Values of $p<0.01$ were considered significant, and NS means that there is no significant ( $P$ $>0.05$ ) between the data. 


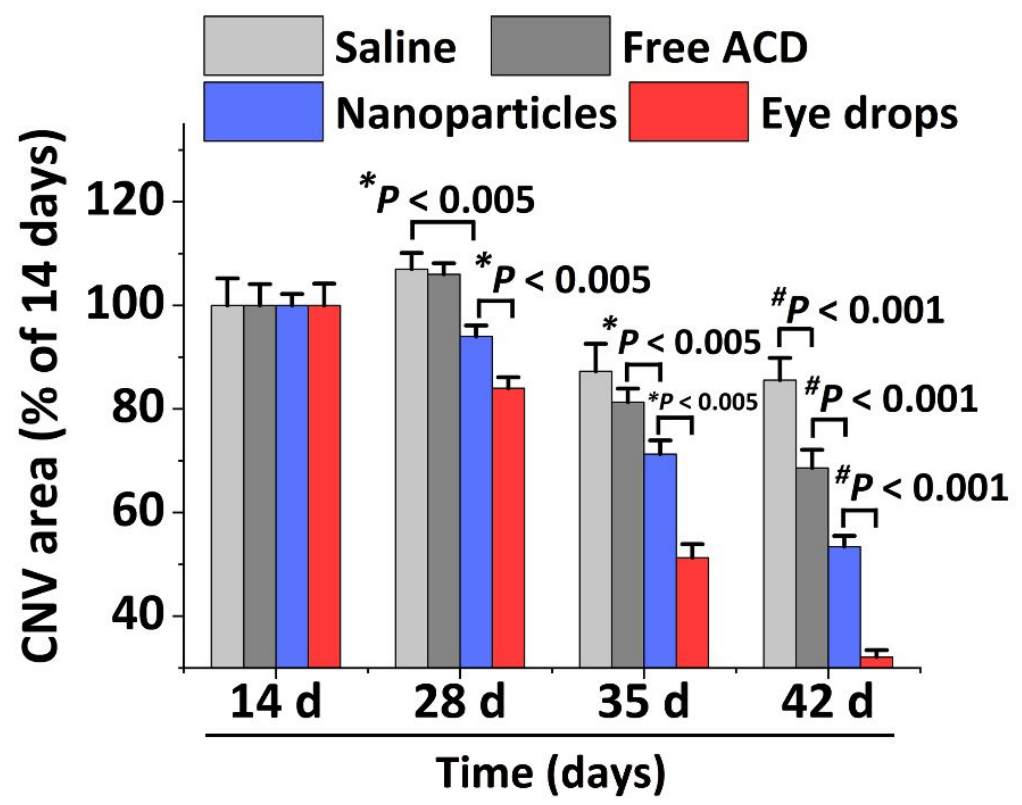

Figure S1. Preliminary quantification of choroidal neovascularization (CNV) in the AMD primate model after 14, 28, 35, and 42 days of the laser injury with the administration of saline, free $A C D, A C D$ nanoparticles, and the eye drops after the 14-day injury. It is necessary to point out that the data for the saline and eye drop groups are those shown in Part a, of Figure 1. After 14 days of the laser photocoagulation to induce AMD in rhesus monkeys, administration of $50 \mu \mathrm{L}$ of saline (control), ACD solution (1 mg/mL), ACD nanoparticles $(1 \mathrm{mg} / \mathrm{mL}$, based on the amount of $A C D$ ), and the eye drops ( $1 \mathrm{mg} / \mathrm{mL}$, based on the amount of ACD) was performed, which was twice a day and lasted 28 days. Fundus fluorescein angiography were taken and quantified after fluorescein injection to evaluate fluorescein leakage associated with CNV lesions at 14, 28, 35, and 42 days. The error bars depict sem (standard error of mean). With $n$ (the number of moneys used) = 3 (saline group), 1 (free ACD), 1 (nanoparticles) and 4 (eye drops group), the data were analyzed by the one-way ANOVA test followed by the post hoc Bonferroni's multiple comparison test. For the CNV area at 42 days (based on $100 \%$ of the 14 day data), we estimated that it was $85.6 \pm 4.3,68.6 \pm 3.5,53.4 \pm 2.1$, and $32.1 \pm 1.4$ for the four sequential groups. The eye drop group displayed a higher anti-CNV activity than the rest three groups. 
Table S1. The degree of injure estimated for both the saline and eye drop groups shown in Figure 1, with the percentage (\%) of Grade IV lesion assessed after 14, 28, 35, 42 days of the treatment. It might be of help to briefly review again here that after 14 days of the laserinduced $A M D$ in seven rhesus monkeys, the administration of saline (control, three monkeys, six eyes) and of eye drops ( $50 \mu \mathrm{L} /$ eye, four monkeys, eight eyes ) was performed, which was twice a day and lasted 28 days. Evidently, the administration of the eye drop decreased the percentage of Grade IV lesions.

\begin{tabular}{ccc}
\hline Days after the laser injury & \multicolumn{2}{c}{ Grade IV (\%) } \\
\cline { 2 - 3 } $\begin{array}{c}\text { (Days of eye drops or saline } \\
\text { treatment) }\end{array}$ & Saline & Eye drops \\
\hline $14(0)$ & 100 & 100 \\
$28(14)$ & 100 & 62.5 \\
$35(21)$ & 83.3 & 25.0 \\
$42(28)$ & 66.7 & 0 \\
\hline
\end{tabular}




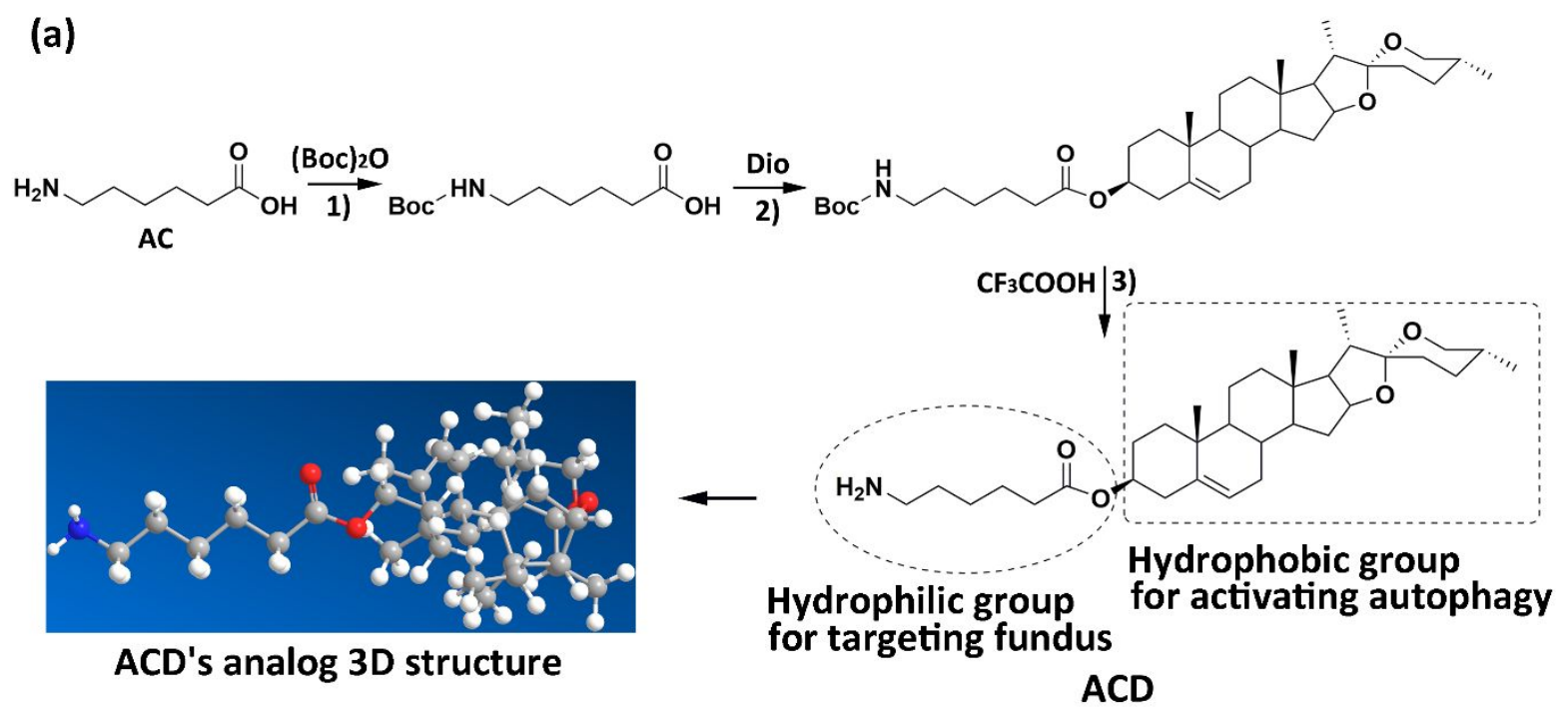

(b)

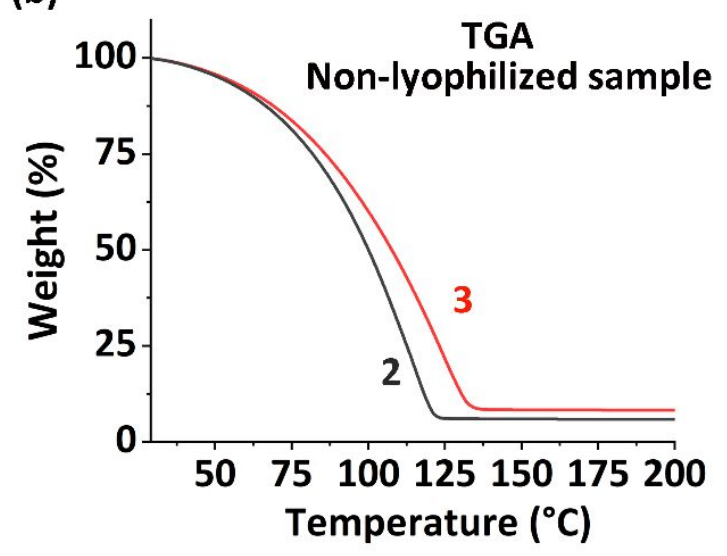

(c)

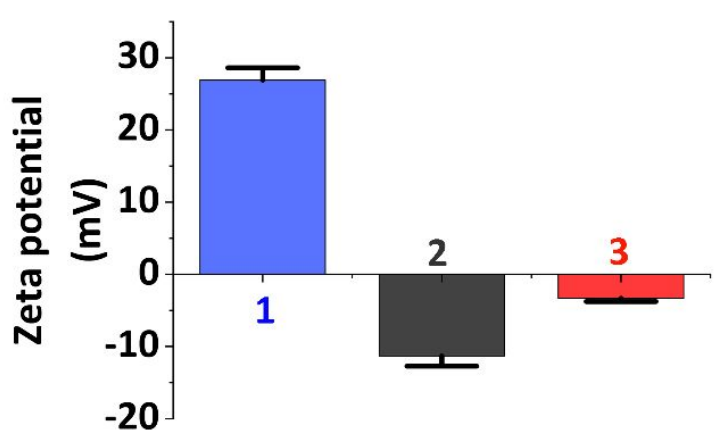

Figure S2-1. Preparation and characterization of eye drops. (a) Schematic illustration of the synthesis of $A C D$. Step 1): (Boc) ${ }_{2} \mathrm{O}, \mathrm{Et}_{3} \mathrm{~N}, \mathrm{CH}_{3} \mathrm{COCH}_{3} \sim \mathrm{H}_{2} \mathrm{O}(\mathrm{v}: \mathrm{v}, 1: 1), 5 \mathrm{~h}, 37^{\circ} \mathrm{C}$. Step 2): DCC, TsOH, DMAP, $\mathrm{CH}_{2} \mathrm{Cl}_{2}, 37^{\circ} \mathrm{C}, 9$ h. Step 3): $\mathrm{CF}_{3} \mathrm{COOH}, \mathrm{CH}_{2} \mathrm{Cl}_{2}, 37^{\circ} \mathrm{C}, 6 \mathrm{~h}$. AC: aminocaproic acid; Dio: $(3 \beta, 25 R)$-spirost-5-en-3-ol (diosgenin). (b) TGA of non-lyophilized calcium alginate hydrogels without (2, grey trace) and with ACD nanoparticles (3, red trace). (c) Zeta potentials (surface charge, results expressed being mean \pm sem (standard error of mean), $n=5$ ) of the nanoparticles ( 1 , blue), calcium alginate hydrogel $(2$, grey), and eye drops $(3$, red). The zeta potentials are $26.90 \pm 1.71$ (1, blue), $-11.32 \pm 1.39$ (2, green) and $-3.32 \pm 0.45 \mathrm{mV}(3$, red), respectively. 


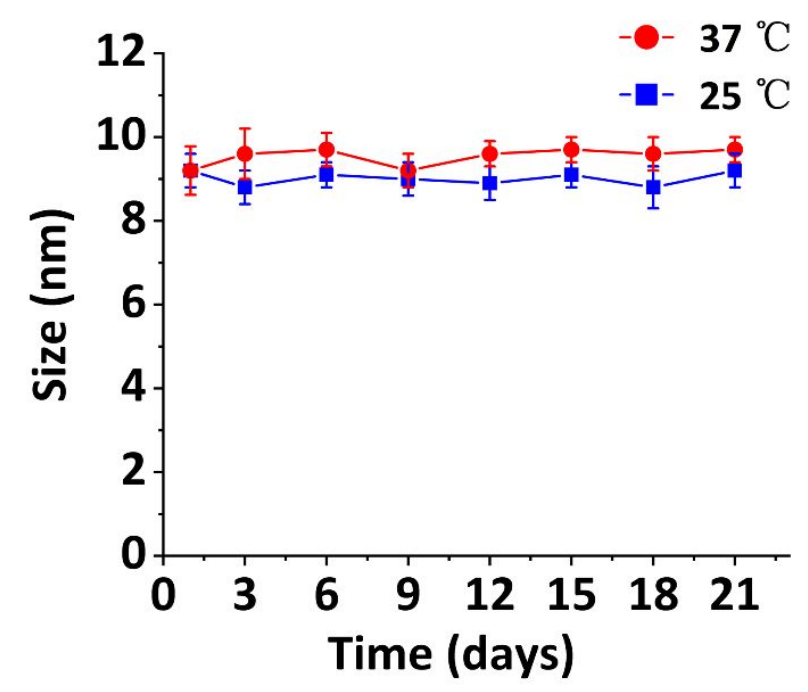

Figure S2-2. The size of ACD nanoparticles in water $(\mathrm{pH}=7.4)$ monitored (by a particle size analyzer) at $37^{\circ} \mathrm{C}$ (red circular symbols) and at $25^{\circ} \mathrm{C}$ (blue square symbols) up to 21 days. The corresponding solid lines are for eye guidance. Each point represents the average of five measurements with \pm sem (standard error of mean) indicated. It is reasonable to conclude that the ACD nanoparticles were quite stable for at least three weeks. 
(a)

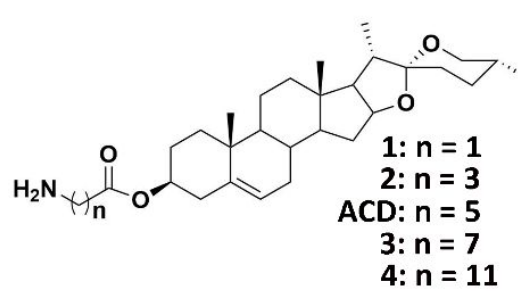

(d)

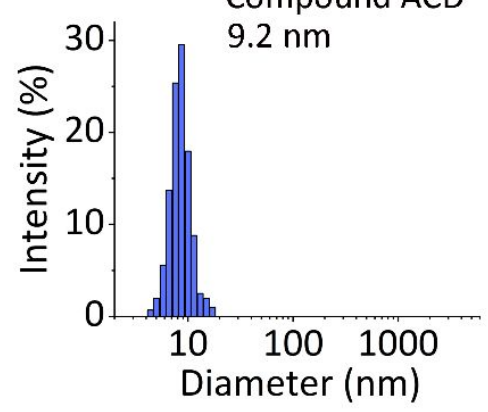

(b)

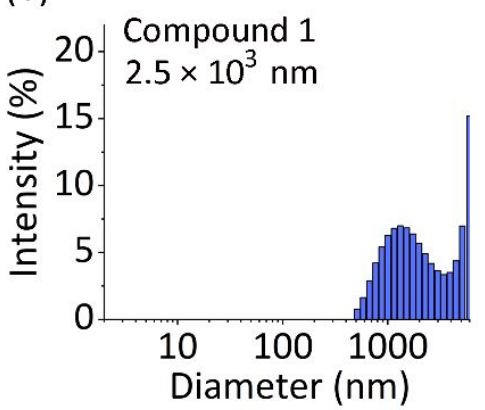

(e)

Compound 3

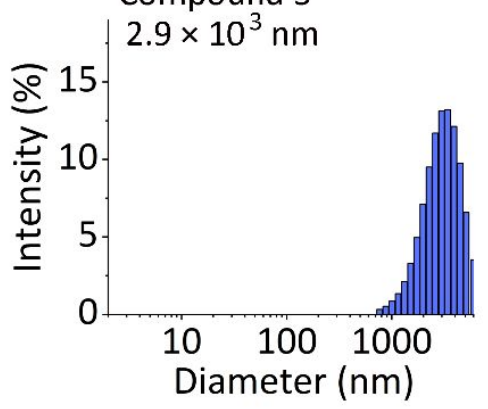

(c)

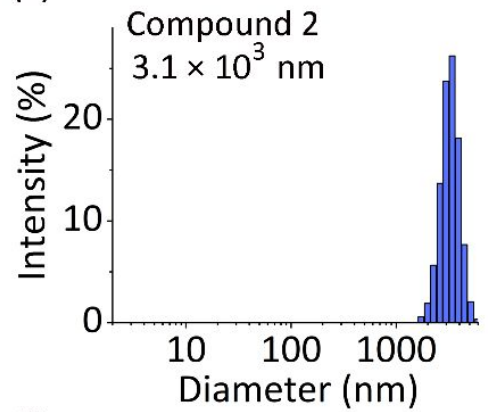

(f)

Compound 4

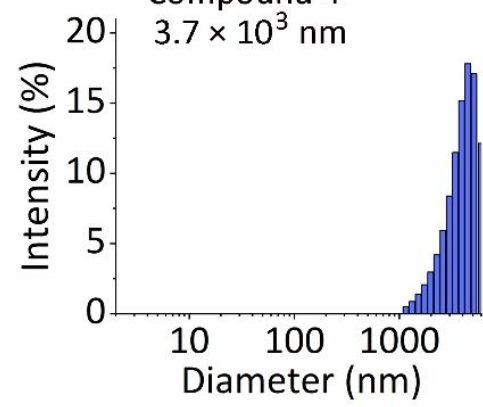

Figure S2-3. Exploration of the self-assembly of five Dio derivatives $\left(\mathrm{H}_{2} \mathrm{~N}-\left(\mathrm{CH}_{2}\right)_{n}-\mathrm{COO}-\right.$ Dio $)$ in water. (a) Chemical structures of the Dio derivatives with glycine ( $n=1$, compound 1$)$, 4aminobutyric acid ( $n=3$, compound 2), 6-aminocaproic acid ( $n=5, A C D), 8$-aminooctanoic acid $(n=7$, compound 3 ), and 12-aminododecanoic acid $(n=11$, compound 4$)$. Each of the compounds $(125 \mathrm{mg}$ ) was firstly dissolved in $1.0 \mathrm{~mL}$ of ethanol; then, the solution was dropwise added into $1.0 \times 10^{2} \mathrm{~mL}$ of deionized water which contained $0.40 \mathrm{~mL}$ of Tween 20 and $0.28 \mathrm{~g}$ of $\beta$-cyclodextrin. The resulting mixture was stirred (at $600 \mathrm{rpms}$ ) for $30 \mathrm{~min}$ at $37^{\circ} \mathrm{C}$. And a particle size analyzer was applied to monitor the self-assembled particles, the mean hydrodynamic diameters of which were $2.5 \times 10^{3} \mathrm{~nm}(\mathrm{~b}$, compound 1$), 3.1 \times 10^{3} \mathrm{~nm}(\mathrm{c}$, compound 2), $9.2 \mathrm{~nm}$ (d, compound ACD), $2.9 \times 10^{3} \mathrm{~nm}$ (e, compound 3), and $3.7 \times 10^{3} \mathrm{~nm}(\mathrm{f}$, compound 4). Evidently, the size of the self-assembled particles from compound $\operatorname{ACD}(n=5)$ is the smallest; it is noteworthy that the solubility of compound 1 and compound 4 is quite limited in ethanol. For the Dio derivatives $\left(\mathrm{H}_{2} \mathrm{~N}-\left(\mathrm{CH}_{2}\right)_{n}-\mathrm{COO}-\mathrm{Dio}\right)$, we chose $A C D(n=5)$ for our biomedical application dealt with in the present study. 

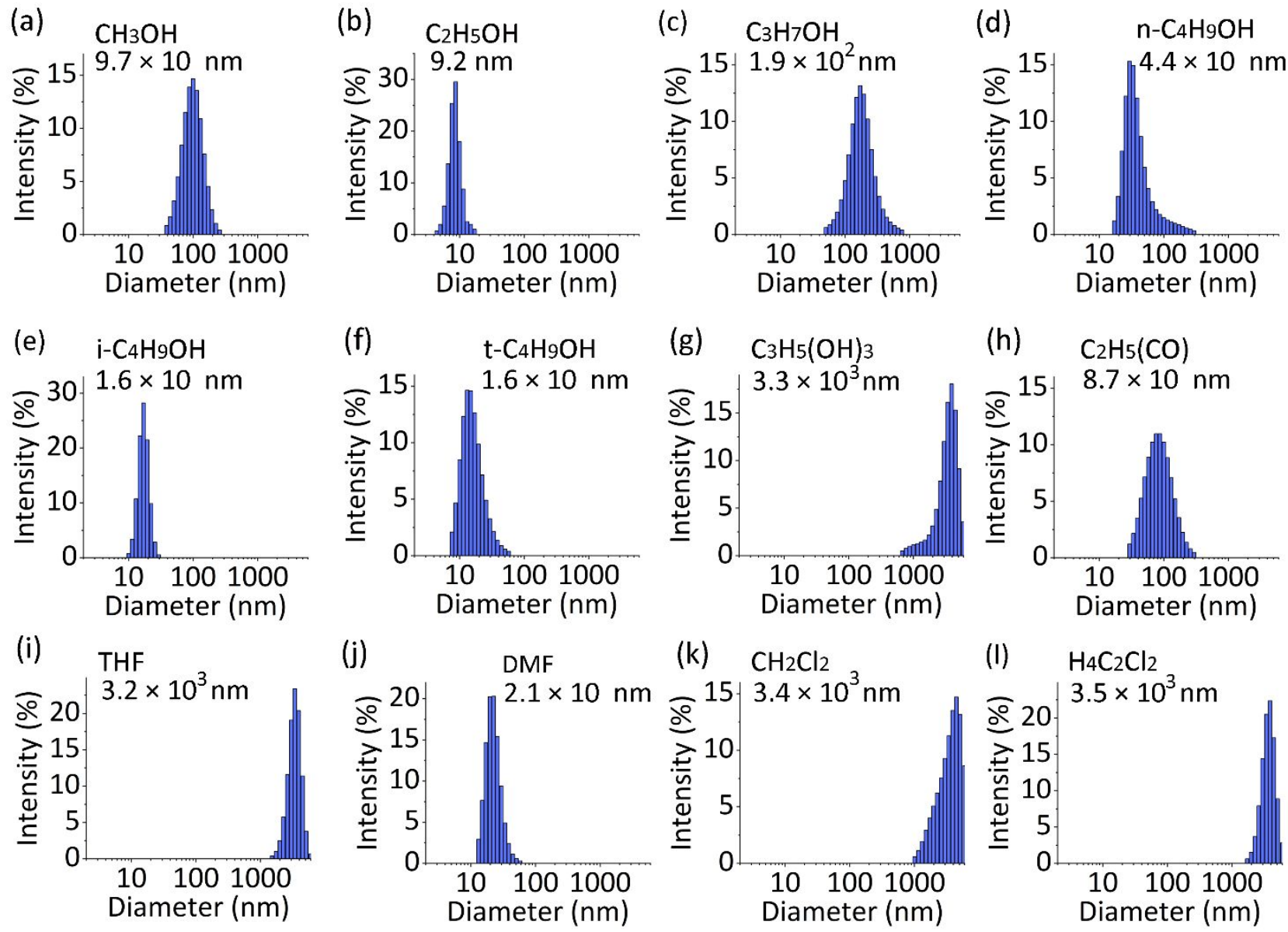

Figure S2-4. Investigation of the self-assembly of ACD in water. ACD (125 mg) was dissolved in $1.0 \mathrm{~mL}$ of methanol $\left(\mathrm{CH}_{3} \mathrm{OH}\right)(\mathrm{a})$, ethanol $\left(\mathrm{C}_{2} \mathrm{H}_{5} \mathrm{OH}\right)(\mathrm{b})$, n-propanol $\left(\mathrm{C}_{3} \mathrm{H}_{7} \mathrm{OH}\right)(c)$, n-butanol (n$\left.\mathrm{C}_{4} \mathrm{H}_{9} \mathrm{OH}\right)(\mathrm{d})$, i-butanol $\left(i-\mathrm{C}_{4} \mathrm{H}_{9} \mathrm{OH}\right)(\mathrm{e})$, t-butanol $\left(\mathrm{t}-\mathrm{C}_{4} \mathrm{H}_{9} \mathrm{OH}\right)(\mathrm{f})$, glycerol $\left(\mathrm{C}_{3} \mathrm{H}_{5}(\mathrm{OH})_{3}\right)(\mathrm{g})$, acetone $\left(\mathrm{C}_{2} \mathrm{H}_{5}(\mathrm{CO})\right)(\mathrm{h})$, tetrahydrofuran (THF) (i), N,N-dimethylformamide (DMF) (j), dichloromethane $\left(\mathrm{CH}_{2} \mathrm{Cl}_{2}\right)(\mathrm{k})$, and 1,2-dichloroethane $\left(\mathrm{H}_{4} \mathrm{C}_{2} \mathrm{Cl}_{2}\right)(\mathrm{I})$. Each solution was added dropwise into $1.0 \mathrm{x}$ $10^{2} \mathrm{~mL}$ of deionized water which contained $0.40 \mathrm{~mL}$ of Tween 20 and $0.28 \mathrm{~g}$ of $\beta$-cyclodextrin. The resulting mixture was stirred (at $600 \mathrm{rpms}$ ) for $30 \mathrm{~min}$ at $37^{\circ} \mathrm{C}$. And a particle size analyzer was applied to monitor the self-assembled particles, the mean hydrodynamic diameters of which were $9.7 \times 10$ (a), 9.2 (b), $1.9 \times 10^{2}$ (c), $4.4 \times 10$ (d), $1.6 \times 10$ (e), $1.6 \times 10$ (f), $3.3 \times 10^{3}$ (g), $8.7 \times 10(\mathrm{~h}), 3.2 \times 10^{3}(\mathrm{i}), 2.1 \times 10(\mathrm{j}), 3.4 \times 10^{3}(\mathrm{k})$, and $3.5 \times 10^{3} \mathrm{~nm}(\mathrm{l})$. Clearly, the use of ethanol resulted in the smallest self-assembled particles of ACD in water, and we chose ethanol for the present application addressed. 

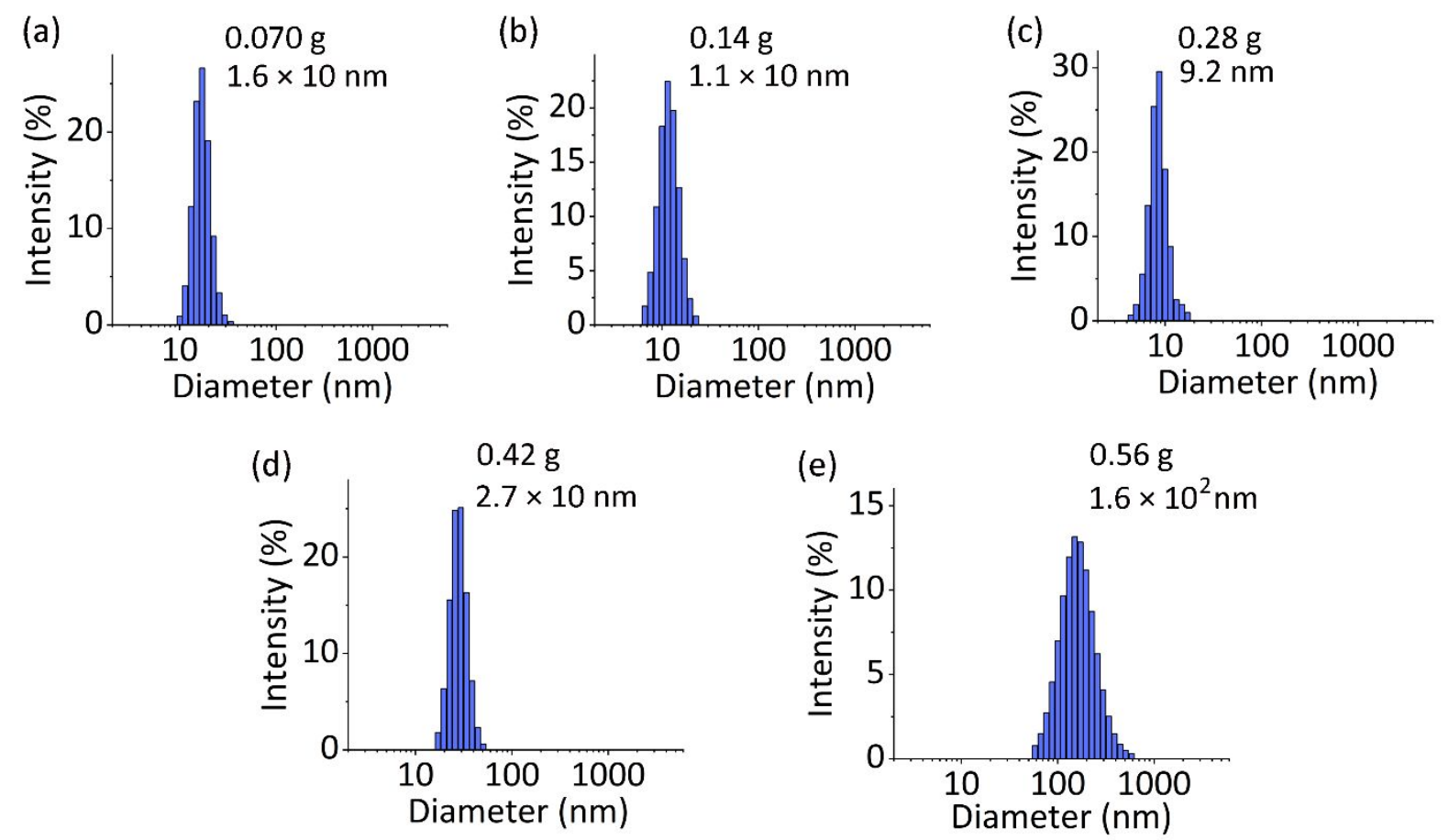

Figure S2-5. Examination of the self-assembly of ACD in water containing five amounts of $\beta$ cyclodextrin. Again, ACD (125 mg) was dissolved in $1.0 \mathrm{~mL}$ of ethanol, the solution was dropwise added into $1.0 \times 10^{2} \mathrm{~mL}$ of deionized water containing $0.40 \mathrm{~mL}$ of Tween 20 and 0.070 (a), 0.14 (b), 0.28 (c), 0.42 (d), and $0.56 \mathrm{~g}$ (e) of $\beta$-cyclodextrin. The resulting mixture was stirred (at $600 \mathrm{rpms}$ ) for $30 \mathrm{~min}$ at $37^{\circ} \mathrm{C}$. And a particle size analyzer was applied to monitor the selfassembled particles, the mean hydrodynamic diameters of which were $1.6 \times 10(\mathrm{a}), 1.1 \times 10(\mathrm{n})$, $9.2(\mathrm{c}), 2.7 \times 10(\mathrm{~d})$, and $1.6 \times 10^{2} \mathrm{~nm}(\mathrm{e})$. For the present application, there seemed to be a reasonable amount range for $\beta$-cyclodextrin (such as 0.14 to $0.28 \mathrm{~g}$ ), while we chose $0.28 \mathrm{~g}$ for the bio-related experiments focused. 

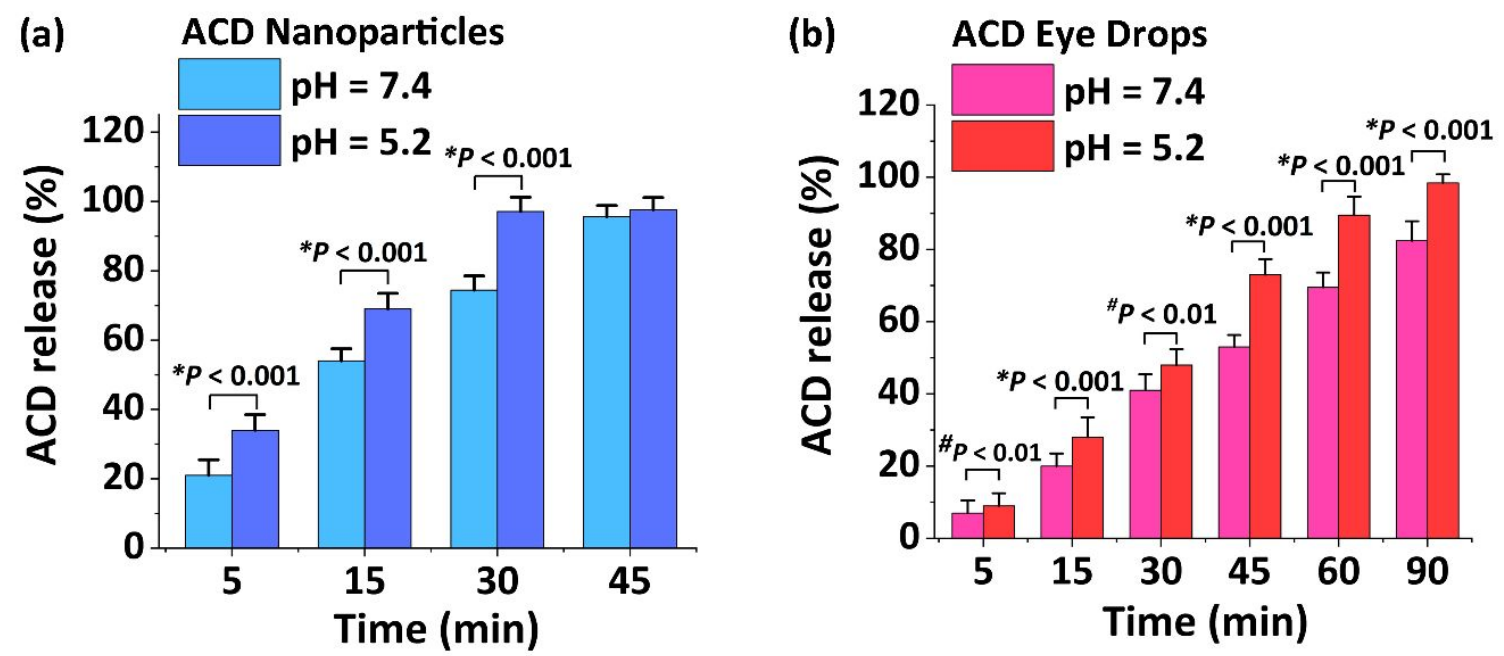

Figure S3. Comparison of the in vitro release of ACD molecules from the Fig. 3 ACD selfassembled nanoparticles solution (a) and from the eye drop solution (b). The release was monitored at $37{ }^{\circ} \mathrm{C}$ under stirring in PBS (pH 7.4) and Tween-treated PBS (pH 5.2) as indicated. Both the self-assembled nanoparticles and the eye drops have a relatively faster release rate in the $\mathrm{pH} 5.2$ environment than in the $\mathrm{pH} 7.4$ environment. The data for (a) and (b) are presented as mean \pm sem and were analyzed using Student $t$ test. 


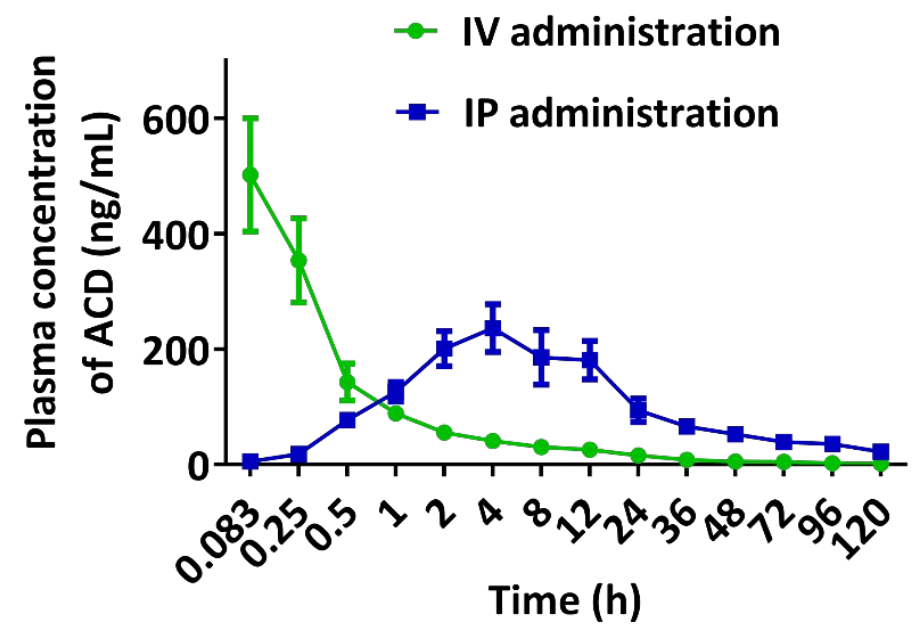

Figure S4. Pharmacokinetic studies of ACD. Concentration-time profiles of ACD in rats' plasma. Our eye drops were administered intravenously $(2 \mathrm{mg} / \mathrm{kg})$ or intraperitoneally $(20 \mathrm{mg} / \mathrm{kg})$ at a single dose to rats. Blood samples $(300 \mu \mathrm{L})$ were collected in heparin-rinsed eppendorf vials from the jugular vein at the indicated time after administration. UHPLC-MS/MS was used to analyze the plasma concentration of ACD. The data are presented as mean $\pm \operatorname{sem}(n=8)$. 
Table S2. Summary of pharmacokinetic data for plasma ACD in rats. Abbreviations: $C_{\text {max }}$ observed maximum concentration; $T_{\max }$, time to $C_{\max } ; T_{1 / 2}$, distribution half-life; $V z / F$, the apparent volume of distribution; $\mathrm{CL} / \mathrm{F}$, clearance; $\mathrm{AUC}_{0-\mathrm{t}}$, area under the concentration-time curve. These pharmacokinetic parameters of ACD were obtained using Phoenix WinNonlin software base on concentration-time data of Figure S4.

\begin{tabular}{lcc}
\hline Pharmacokinetic parameter & \multicolumn{2}{c}{ Dose $(\mathrm{mg} / \mathrm{kg})$} \\
\cline { 2 - 3 } & $5(\mathrm{IP})$ & 1 (IV) \\
\hline $\mathrm{C}_{\max }(\mathrm{ng} / \mathrm{mL})$ & 236.6 & - \\
$\mathrm{T}_{\max }(\mathrm{h})$ & 3.5 & - \\
$\mathrm{T}_{1 / 2}(\mathrm{~h})$ & 26.0 & 12.1 \\
$\mathrm{Vz} / \mathrm{F}(\mathrm{mL} / \mathrm{kg})$ & 198967.6 & 26551.9 \\
$\mathrm{CL} / \mathrm{F}(\mathrm{mL} /(\mathrm{h} \cdot \mathrm{kg}))$ & 2289.1 & 820.6 \\
$\mathrm{AUC}_{0-\mathrm{t}}(\mathrm{ng} \cdot \mathrm{h} / \mathrm{mL})$ & 8254.2 & 1240.8 \\
\hline
\end{tabular}


(a)
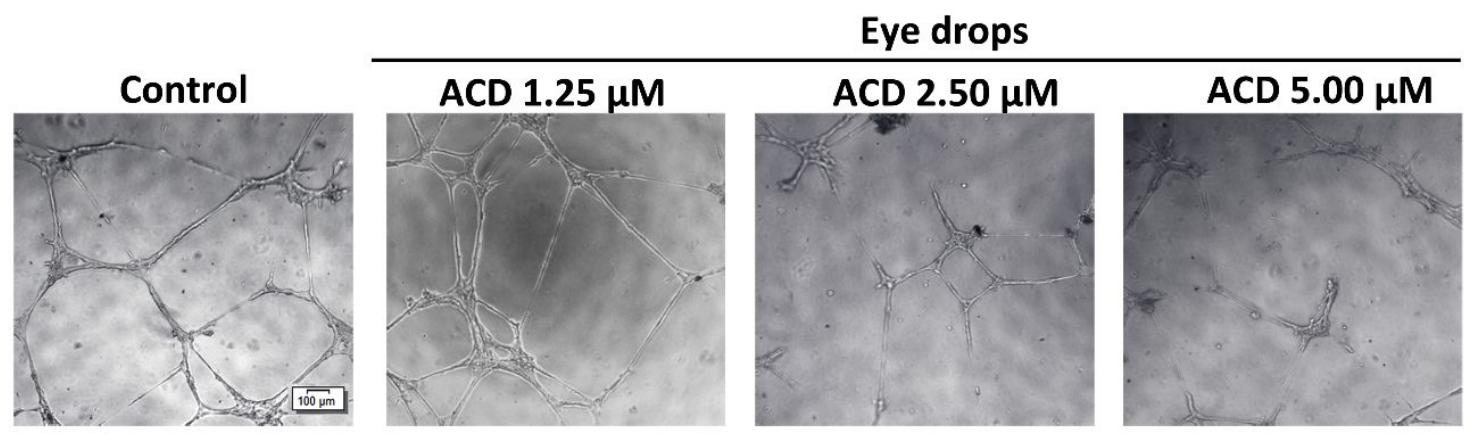

(b)
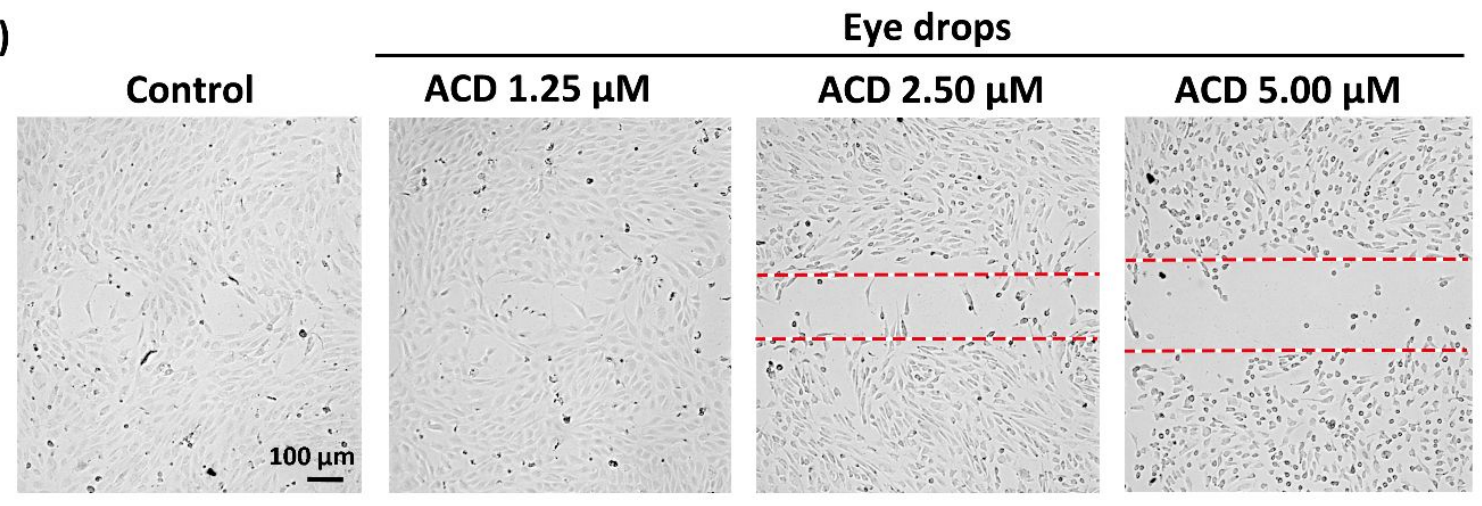

Figure S5-1. Representative optical microscope images to illustrate (a) the formation of tubularlike structures and (b) cell migration. HUVECs were treated with the mixtures of $20 \mathrm{ng} / \mathrm{mL}$ VEGF and $0.00 \mu \mathrm{M}$ (Control), $1.25 \mu \mathrm{M}, 2.50 \mu \mathrm{M}$ or $5.00 \mu \mathrm{M}$ eye drops. Optical microscope images of tubule formation (a) and migration (b) of HUVECs were acquired after 24 treatment. The experiments were repeated five times $(n=5)$. 

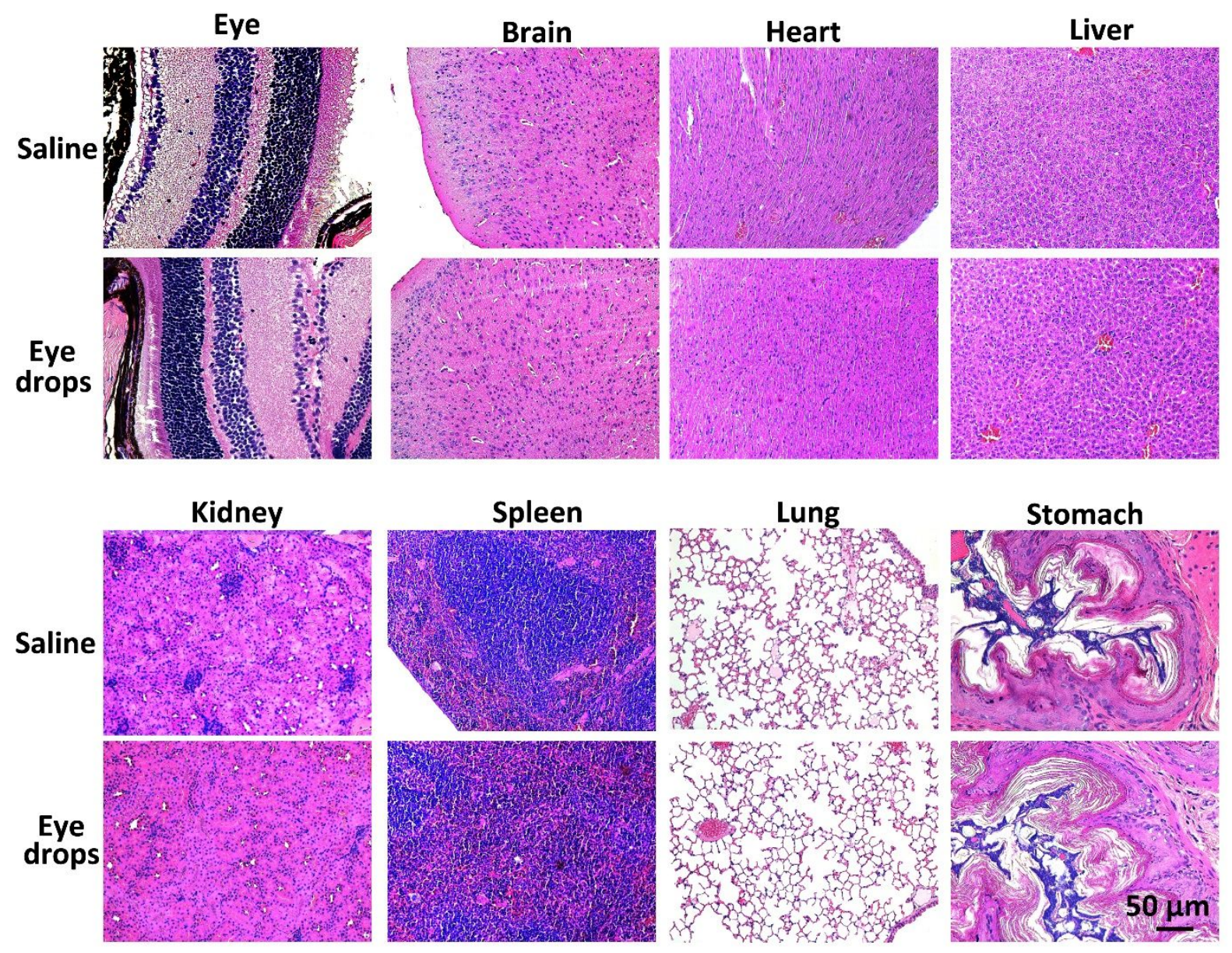

Figure S5-2. In vivo toxicity study with mice by representative H\&E-stained (hematoxylin and eosin stained) optical microscopy. Images shown here are, in sequence, for eye, brain, heart, liver, kidney, spleen, lungs, and stomach. The mice were administrated with saline (control, top panels) and the eye drops ( $10 \mu \mathrm{L} / \mathrm{eye}$, bottom panels) twice a day for 28 days. The tissues shown were stained with H\&E for histological examination. Each group contained 7 mice. Evidently, the eye drops displayed no obvious toxicity to these organs. 


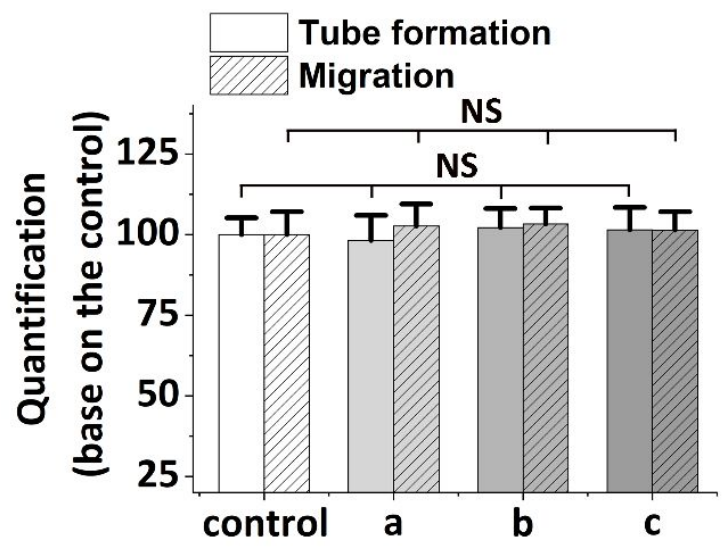

Figure S5-3. Exploration of the amount effect of EDTA calcium via in vitro anti-angiogenic activity of HUVECs. According to the control as $100 \%$, the number of tubular structures formed (non-slashed columns) and cell migration (slashed columns) have been quantified based on the use of three samples, $a, b$, and $c$ with an increased order of EDTA calcium. A stock solution, which was similar to the eye drop stock solution but without $A C D$, was prepared with $160 \mathrm{mM}$ EDTA, $1.90 \mathrm{mM} \beta$-cyclodextrin, $2.87 \mathrm{mM}$ Tween 20 , and $16.0 \mathrm{mg} / \mathrm{mL}$ sodium alginate. Subsequently, 53,105 , and $158 \mu \mathrm{L}$ of the stock solution were diluted individually in three PBS solutions to reach a total volume of $1.00 \mathrm{~mL}$. An aliquot $(25 \mu \mathrm{L})$ of each resulting solution was then mixed with $475 \mu \mathrm{L}$ PBS to get Samples $a, b$, and $c$ with a total volume of $500 \mu \mathrm{L}$. Accordingly, Sample a--b--c had respective 105--211--421 $\mu$ M EDTA calcium, 1.30--2.60--5.20 $\mu \mathrm{M} \beta$-cyclodextrin, 1.89--3.78--7.56 $\mu \mathrm{M}$ Tween 20, and 10.5--21.1--42.1 $\mu \mathrm{g} / \mathrm{mL}$ sodium alginate. Monolayer cultures of HUVECs were incubated in the presence of VEGF $(20.0 \mathrm{ng} / \mathrm{mL})$ and PBS $(500 \mu \mathrm{L})$ (0.00 (control), 105 (a), 211 (b), and 421 (c) $\mu \mathrm{M}$ EDTA calcium) for $24 \mathrm{~h}$. No significant (NS) difference was obtained. The data are presented as mean $\pm \operatorname{sem}(n=5)$, and were analyzed using one-way ANOVA followed by Bonferroni's post hoc multiple comparison tests. Evidently, the three samples, a, b, and c, displayed no significant effect on angiogenesis of HUVEC. 


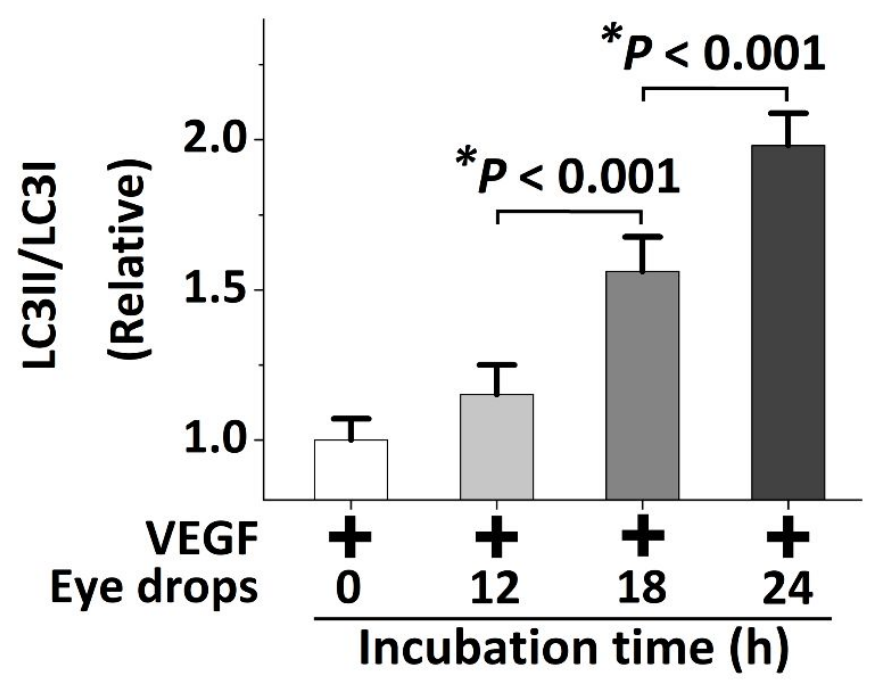

Figure S6-1. The quantitative analysis of LC3II/LC3I in Figure 6a Western blots. The Western blot study for LC3II/LC3I was obtained with VEGF-incubated HUVECs, treated with $5 \mu \mathrm{M}$ eye drops (based on the amount of $A C D$ ) for $0,12,18$, and $24 \mathrm{~h}$. The data were analyzed by one-way ANOVA with Dunnett's multiple comparison test. Error bars depict sem. $n=5$. 
(a)

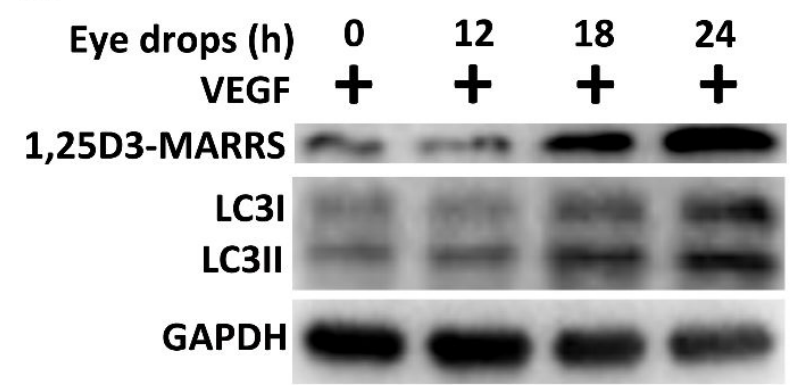

(c)

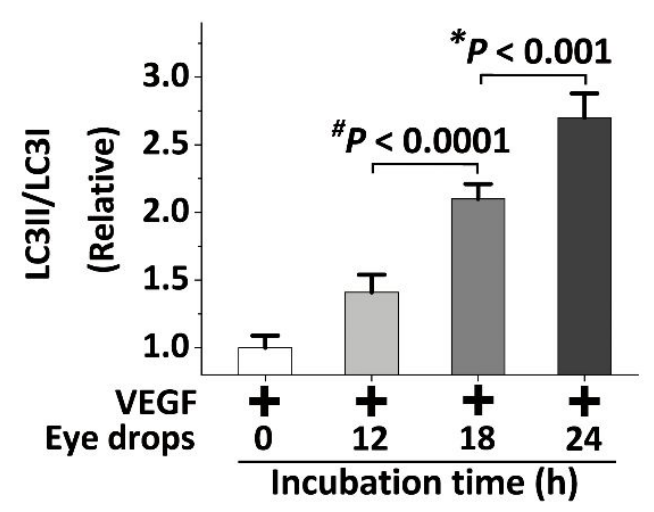

(b)

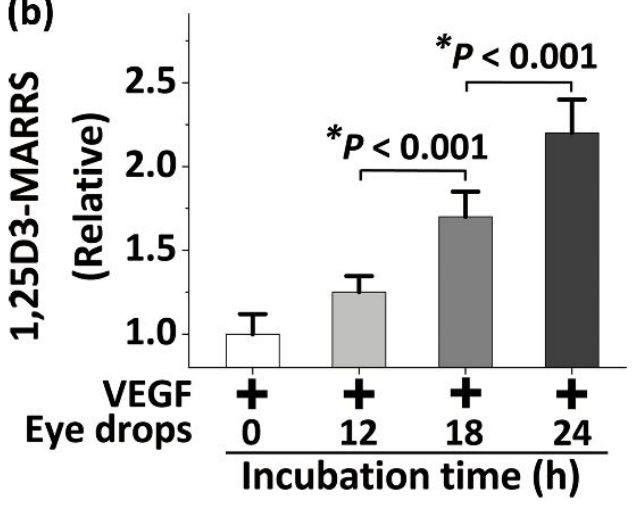

Figure S6-2. Eye drops promoting the expression of protein $1,25 D_{3}-M A R R S$ and autophagy of human retinal pigment epithelium cells (RPEC) which were incubated with VEGF $(20 \mathrm{ng} / \mathrm{mL})$ (similar to those with HUVEC shown in Figure 6). (a) Western blot analysis of protein $1,25 \mathrm{D}_{3^{-}}$ MARRS, LC3I and LC3II in RPEC before $(0 \mathrm{~h})$ and after 12, 18, and $24 \mathrm{~h}$ of the eye drop treatment (5 $\mu \mathrm{M})$. GAPDH (Glyceraldehyde 3-phosphate dehydrogenase) was used as a loading control for Western Blot to normalize the level of the protein. Corresponding quantitative analysis of 1,25D3-MARRS (b) and LC3II/LC3 (c) was performed as well. 
(ai)

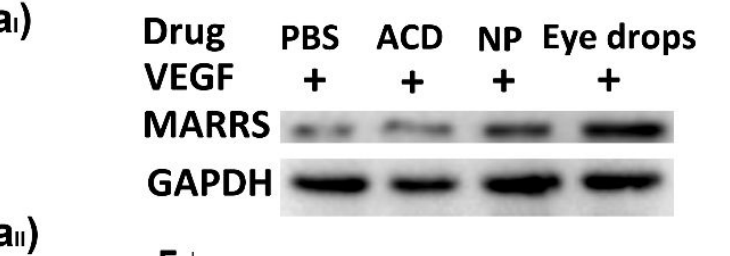

(an)

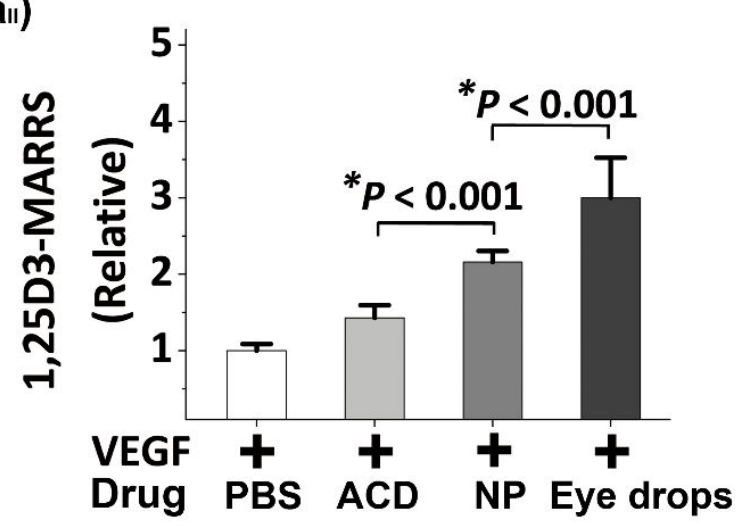

(b)

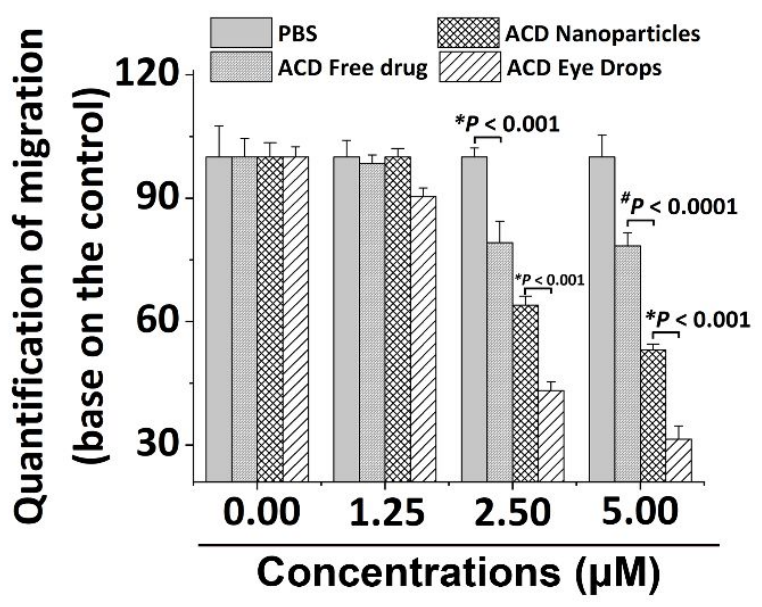

Figure S6-3. Exploration of the effects of free ACD, nanoparticles, and eye drops on the expression of Protein $1,25 D_{3}$-MARRS and cell migration in the HUVECs. $\left(a_{1}\right)$ Western blot analysis of protein $1,25 D_{3}$-MARRS in HUVECs after PBS, free ACD (ACD molecules dissolved in PBS, $5 \mu \mathrm{M}$, based on the amount of $\mathrm{ACD})$, nanoparticles ( $5 \mu \mathrm{M}$, based on the amount of $A C D$ ), and the eye drop ( $5 \mu \mathrm{M}$, based on the amount of ACD) treatment of $24 \mathrm{~h}$. GAPDH (Glyceraldehyde 3-phosphate dehydrogenase) was used as a loading control for Western Blot to normalize the level of the protein. $\left(a_{\|}\right)$Corresponding quantitative of $1,25 D_{3}-$ MARRS. (b) Quantification of cell migration, according to the control as $100 \%$. Monolayer cultures of HUVECs were incubated with mixtures of VEGF $(20 \mathrm{ng} / \mathrm{mL})$ and PBS, free ACD, nanoparticles, and the eye drop $(0.00,1.25,2.50$, or $5.00 \mu \mathrm{M}$, based on the amount of $A C D)$ for $24 \mathrm{~h}$. The data for $\left(a_{\|}\right)$and $(b)$ are presented as mean $\pm \operatorname{sem}(n=5)$, and were analyzed using one-way ANOVA followed by Bonferroni's post hoc multiple comparison tests. Evidently, the eye drops have a stronger ability to inhibit angiogenesis and promote Protein $1,25 D_{3}$-MARRS expression compared with free ACD and nanoparticles. 
(a)

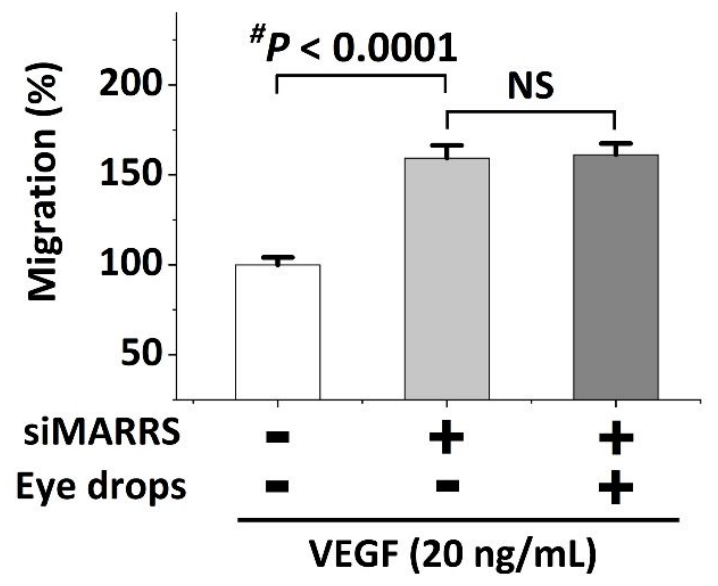

(b)

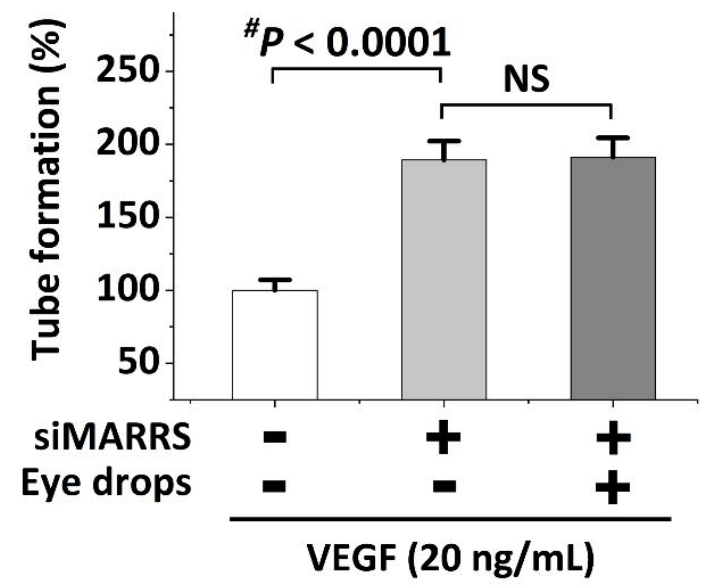

Figure S7. The quantitative analysis of cell migration (a) and tuber formation (b) of Figure 7b and c. According to the control as $100 \%$. Part a and b, results are represented as mean $\pm \operatorname{sem}$ (n $=5$ ), and data were analyzed by one-way ANOVA with Dunnett's multiple comparison test. NS: no significance. 


\section{Note}

The Design and Preparation of ACD Eye Drops. 1,25D $\mathrm{D}_{3}$-membrane-associated rapid response

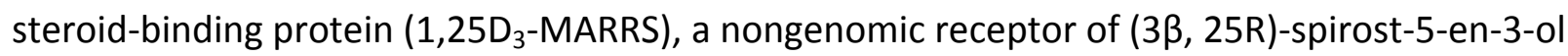
(diosgenin) derivatives, is a potential antiangiogenic target due to the activation of autophagy. ${ }^{22,23}$ Diosgenin (Dio), a natural plant extract mainly from roots of wild yam, ${ }^{24}$ have received more and more attention and showed the significant antiangiogenic capacity as its potent autophagy-inducing activity. ${ }^{21-23,}$ Resents studies found that Dio abolished the expression of VEGF in PC-3 cells and tube formation of endothelial cells, inhibited amyloid- $\beta$ aggregation of MC65 cells in a dose-dependent manner. ${ }^{25,26}$ However, their use in ocular neovascular diseases is limited as poor water solubility and permeability of corneal barrier as well blood-eye barrier. An optimal antiangiogenic formulation of Dio that accumulates in the fundus by eye drops yet remains to be established.

Usually, the lipophilic corneal epithelium, which is 6 - 7 cell layers thick (50-90 $\mu \mathrm{m})$, is the main barriers of drug absorption into the eye. ${ }^{27}$ Due to amino acids are required for the synthesis of protein in all living cells, membrane proteins exist to transport essential amino acids across lipoidal membranes. ${ }^{28}$ It is very promising for the targeted delivery of drugs to the fundus through amino acid transporters as their wide substrate acceptability and high capacity in the retina and cornea. ${ }^{28}$ Aminocaproic acid, a derivative of lysine, permeated effectively the cornea in eye drop administration. ${ }^{29}$ Meanwhile, it reduced patient leakage and bleeding of blood vessels in blood-brain barrier and cardiac surgical procedures. ${ }^{30,31}$ The leakage and bleeding of blood vessels are the main pathological features of AMD. Hence, we performed the modify of Dio with aminocaproic acid to obtain ACD for enhance the permeability and therapeutic activity of the agent. Interesting, the ACD could self-assemble into nanoparticles in aqueous media as an amphipathic property.

Therapeutics release from nanoparticles is fast and not controllable within the administration process, and the undesired leakage of nanoparticles makes them inefficient. ${ }^{32}$ Hydrogels provide a flexible platform for the design of ocular drug delivery systems as better bioavailability and a prolonged-release of drugs. ${ }^{33}$ Hydrogel improves drug contact time and duration of action compared with the drug solution as it retains in the precorneal pocket. ${ }^{34}$ In 
this study, we designed a biocompatible functional eye drop, ACD self-assembled nanoparticles encapsulated in a biocompatible calcium alginate hydrogel that enable sustained release of ACD. Our eye drops increased the contact time of the drug with the eye surface and effectively penetrate the cornea, and rapidly accumulate in retina and choroid which are the site of the occurrence of AMD.

\section{REFERENCES}

(1) Huang, B.; Du, D.; Zhang, R.; Wu, X.; Xing, Z.; He, Y.; Huang, W., Synthesis, Characterization and Biological Studies of Diosgenyl Analogues. Bioorg. Med. Chem. Lett. 2012, 22, 7330-7334.

(2) Huang, B. Z.; Xin, G.; Ma, L. M.; Wei, Z. L.; Shen, Y.; Zhang, R.; Zheng, H. J.; Zhang, X. H.; Niu, H.; Huang, W., Synthesis, Characterization, and Biological Studies of Diosgenyl Analogs. J. Asian. Nat. Prod. Res. 2017, 19, 272-298.

(3) Xin, G.; Wei, Z.; Ji, C.; Zheng, H.; Gu, J.; Ma, L.; Huang, W.; Morris-Natschke, S. L.; Yeh, J. L.; Zhang, R.; Qin, C.; Wen, L.; Xing, Z.; Cao, Y.; Xia, Q.; Li, K.; Niu, H.; Lee, K. H.; Huang, W., Xanthohumol Isolated from Humulus Lupulus Prevents Thrombosis without Increased Bleeding Risk by Inhibiting Platelet Activation and Mtdna Release. Free Radic. Biol. Med. 2017, 108, 247257.

(4) Zhang, M.; Zhang, J.; Yan, M.; Li, H.; Yang, C.; Yu, D., Recombinant Anti-Vascular Endothelial Growth Factor Fusion Protein Efficiently Suppresses Choridal Neovasularization in Monkeys. Mol. Vis. 2008, 14, 37-49.

(5) Handa, J. T.; Rickman, C. B.; Dick, A. D.; Gorin, M. B.; Miller, J. W.; Toth, C. A.; Ueffing, M.; Zarbin, M.; Farrer, L. A., A Systems Biology Approach Towards Understanding and Treating NonNeovascular Age-Related Macular Degeneration. Nat. Commun. 2019, 10, 3347.

(6) Ehrenberg, M.; Benny, O., Evolving Multidimensional Pharmacological Approaches to Cnv Therapy in Amd. Curr. Eye Res. 2018, 43, 147-154.

(7) Ji, W.; Yu, D.; Yang, P.; Fang, P.; Cao, Y.; Li, H.; Xie, N.; Yan, S., Recombinant Humanized AntiVascular Endothelial Growth Factor Monoclonal Antibody Efficiently Suppresses Laser-Induced Choroidal Neovascularization in Rhesus Monkeys. Eur. J. Pharm. Sci. 2017, 109, 624-630. 
(8) Mitra, R. N.; Gao, R.; Zheng, M.; Wu, M. J.; Voinov, M. A.; Smirnov, A. I.; Smirnova, T. I.; Wang,

K.; Chavala, S.; Han, Z., Glycol Chitosan Engineered Autoregenerative Antioxidant Significantly Attenuates Pathological Damages in Models of Age-Related Macular Degeneration. ACS Nano 2017, 11, 4669-4685.

(9) Sng, C. C. A.; Cheung, C. Y.; Man, R. E.; Wong, W.; Lavanya, R.; Mitchell, P.; Aung, T.; Wong, T. Y., Influence of Diabetes on Macular Thickness Measured Using Optical Coherence Tomography: The Singapore Indian Eye Study. Eye 2012, 26, 690-698.

(10) Chen, X.; Sun, J.; Zhao, H.; Yang, K.; Zhu, Y.; Luo, H.; Yu, K.; Fan, H.; Zhang, X., Theranostic System Based on Nay (Mn) F4:Yb/Er Upconversion Nanoparticles with Multi-Drug Resistance Reversing Ability. J. Mater. Chem. B 2018, 6, 3586-3599.

(11) Zhang, H.; Zhu, Y.; Qu, L.; Wu, H.; Kong, H.; Yang, Z.; Chen, D.; Makila, E.; Salonen, J.; Santos, H. A.; Hai, M.; Weitz, D. A., Gold Nanorods Conjugated Porous Silicon Nanoparticles Encapsulated in Calcium Alginate Nano Hydrogels Using Microemulsion Templates. Nano Lett. 2018, 18, 14481453.

(12) Du, D.; Gao, B.; Xin, G.; Sun, A.; Huang, B.; Zhang, R.; Xing, Z.; Chen, Q.; He, Y.; Huang, W., Determination of Deltonin in Rat Plasma by Using Hplc-Ms/Ms and the Application of This Method in Pharmacokinetic Studies. J. Chromatogr. B 2013, 931, 1-5.

(13) Tong, Q.; Zhao, Q.; Qing, Y.; Hu, X.; Jiang, L.; Wu, X., Deltonin Inhibits Angiogenesis by Regulating Vegfr2 and Subsequent Signaling Pathways in Endothelial Cells. Steroids 2015, 96, 3036.

(14) Tong, Q.; Qing, Y.; Wu, Y.; Hu, X.; Jiang, L.; Wu, X., Dioscin Inhibits Colon Tumor Growth and Tumor Angiogenesis through Regulating Vegfr2 and Akt/Mapk Signaling Pathways. Toxicol. Appl. Pharmacol. 2014, 281, 166-173.

(15) Wei, Z.; Xin, G.; Wang, H.; Zheng, H.; Ji, C.; Gu, J.; Ma, L.; Qin, C.; Xing, Z.; Niu, H.; Huang, W., The Diosgenin Prodrug Nanoparticles with Ph-Responsive as a Drug Delivery System Uniquely Prevents Thrombosis without Increased Bleeding Risk. Nanomedicine : nanotechnology, biology, and medicine 2018, 14, 673-684. 
(16) Wang, H.; Lin, C. J.; Lee, C.; Lin, Y.; Tseng, Y.; Hsieh, C.; Chen, C.; Tsai, C.; Hsieh, C.; Shen, J., Fluorescent Gold Nanoclusters as a Biocompatible Marker for in Vitro and in Vivo Tracking of Endothelial Cells. ACS Nano 2011, 5, 4337-4344.

(17) Ali, M. R.; Wu, Y.; Ghosh, D.; Do, B. H.; Chen, K.; Dawson, M. R.; Fang, N.; Sulchek, T. A.; ElSayed, M. A., Nuclear Membrane-Targeted Gold Nanoparticles Inhibit Cancer Cell Migration and Invasion. ACS Nano 2017, 11, 3716-3726.

(18) Xin, G.; Wei, Z.; Ji, C.; Zheng, H.; Gu, J.; Ma, L.; Huang, W.; Morris-Natschke, S. L.; Yeh, J. L.; Zhang, R.; Qin, C.; Wen, L.; Xing, Z.; Cao, Y.; Xia, Q.; Lu, Y.; Li, K.; Niu, H.; Lee, K. H.; Huang, W., Metformin Uniquely Prevents Thrombosis by Inhibiting Platelet Activation and Mtdna Release. Sci. Rep. 2016, 6, 36222.

(19) Ouseph, M. M.; Huang, Y.; Banerjee, M.; Joshi, S.; MacDonald, L.; Zhong, Y.; Liu, H.; Li, X.; Xiang, B.; Zhang, G.; Komatsu, M.; Yue, Z.; Li, Z.; Storrie, B.; Whiteheart, S. W.; Wang, Q. J., Autophagy Is Induced Upon Platelet Activation and Is Essential for Hemostasis and Thrombosis. Blood 2015, 126, 1224-1233.

(20) Lin, Y.; Qiao, S.; Wang, Y.; Zhang, R.; An, H.; Ma, Y.; Rajapaksha, R. Y. J.; Qiao, Z.; Wang, L.; Wang, H., An in Situ Intracellular Self-Assembly Strategy for Quantitatively and Temporally Monitoring Autophagy. ACS Nano 2017, 11, 1826-1839.

(21) Tohda, C.; Urano, T.; Umezaki, M.; Nemere, I.; Kuboyama, T., Diosgenin Is an Exogenous Activator of 1,25d3-Marrs/Pdia3/Erp57 and Improves Alzheimer's Disease Pathologies in 5xfad Mice. Sci. Rep. 2012, 2, 535.

(22) Turano, C.; Gaucci, E.; Grillo, C.; Chichiarelli, S., Erp57/Grp58: A Protein with Multiple Functions. Cell. Mol. Biol. Lett. 2011, 16, 539-563.

(23) Grotemeier, A.; Alers, S.; Pfisterer, S. G.; Paasch, F.; Daubrawa, M.; Dieterle, A.; Viollet, B.; Wesselborg, S.; Proikas-Cezanne, T.; Stork, B., Ampk-Independent Induction of Autophagy by Cytosolic Ca2+ Increase. Cell. Signal. 2010, 22, 914-925.

(24) Jiang, S.; Fan, J.; Wang, Q.; Ju, D.; Feng, M.; Li, J.; Guan, Z.-b.; An, D.; Wang, X.; Ye, L., Diosgenin Induces Ros-Dependent Autophagy and Cytotoxicity Via Mtor Signaling Pathway in Chronic Myeloid Leukemia Cells. Phytomedicine 2016, 23, 243-252. 
(25) Chen, P. S.; Shih, Y. W.; Huang, H. C.; Cheng, H. W., Diosgenin, a Steroidal Saponin, Inhibits Migration and Invasion of Human Prostate Cancer Pc-3 Cells by Reducing Matrix Metalloproteinases Expression. PloS one 2011, 6, e20164.

(26) Chojnacki, J. E.; Liu, K.; Saathoff, J. M.; Zhang, S., Bivalent Ligands Incorporating Curcumin and Diosgenin as Multifunctional Compounds against Alzheimer's Disease. Bioorg. Med. Chem. 2015, 23, 7324-7331.

(27) Rathore, M. S., Drug Delivery Enhancement Strategies through Cornea: A Review. Asian J. Pharm. 2016, 1, 40-49.

(28) HARIHARAN, S.; THAKKAR, N. R.; MITRA, A. K., Transporter-Targeted Drug Delivery to the Retina. Retina Today 2009, 4, 57-62.

(29) Allingham, R. R.; Williams, P. B.; Crouch, E. R., Jr.; Loewy, D. M.; Demkowski, H. C., Topically Applied Aminocaproic Acid Concentrates in the Aqueous Humor of the Rabbit in Therapeutic Levels. Arch. Ophthalmol. 1987, 105, 1421-1423.

(30) Marcos-Contreras, O. A.; de Lizarrondo, S. M.; Bardou, I.; Orset, C.; Pruvost, M.; Anfray, A.; Frigout, Y.; Hommet, Y.; Lebouvier, L.; Montaner, J., Hyperfibrinolysis Increases Blood-Brain Barrier Permeability by a Plasmin-and Bradykinin-Dependent Mechanism. Blood 2016, 128, 24232434.

(31) Ipema, H. J.; Tanzi, M. G., Use of Topical Tranexamic Acid or Aminocaproic Acid to Prevent Bleeding after Major Surgical Procedures. Ann. Pharmacother. 2012, 46, 97-107.

(32) Reichle, M. L., Complications of Intravitreal Steroid Injections. Optometry 2005, 76, 450-460. (33) Chouhan, G.; Moakes, R. J. A.; Esmaeili, M.; Hill, L. J.; deCogan, F.; Hardwicke, J.; Rauz, S.; Logan, A.; Grover, L. M., A Self-Healing Hydrogel Eye Drop for the Sustained Delivery of Decorin to Prevent Corneal Scarring. Biomaterials 2019, 210, 41-50.

(34) Chang, D.; Park, K.; Famili, A., Hydrogels for Sustained Delivery of Biologics to the Back of the Eye. Drug Discov. Today 2019, 24, 1470-1482. 